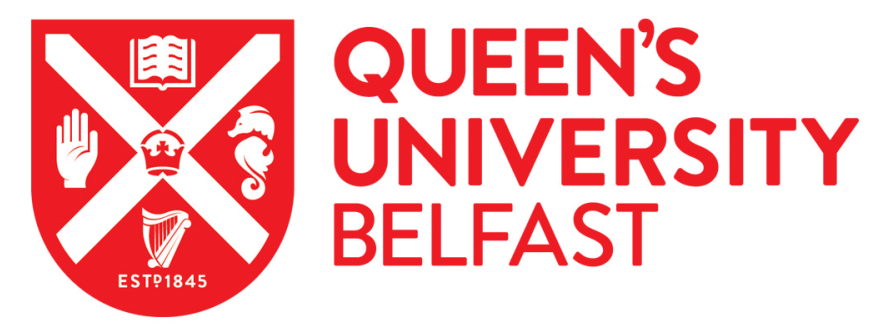

\title{
Comparison analysis on damping mechanisms of power systems with induction generator based wind power generation
}

Bu, S. Q., Zhang, X., Zhu, J. B., \& Liu, X. (2018). Comparison analysis on damping mechanisms of power systems with induction generator based wind power generation. International Journal of Electrical Power and Energy Systems, 97. https://doi.org/10.1016/j.ijepes.2017.10.029

Published in:

International Journal of Electrical Power and Energy Systems

Document Version:

Peer reviewed version

Queen's University Belfast - Research Portal:

Link to publication record in Queen's University Belfast Research Portal

Publisher rights

(C) 2017 Elsevier Ltd.

This manuscript version is made available under the CC-BY-NC-ND 4.0 license http://creativecommons.org/licenses/by-nc-nd/4.0/,which permits distribution and reproduction for noncommercial purposes, provided the author and source are cited.

\section{General rights}

Copyright for the publications made accessible via the Queen's University Belfast Research Portal is retained by the author(s) and / or other copyright owners and it is a condition of accessing these publications that users recognise and abide by the legal requirements associated with these rights.

Take down policy

The Research Portal is Queen's institutional repository that provides access to Queen's research output. Every effort has been made to ensure that content in the Research Portal does not infringe any person's rights, or applicable UK laws. If you discover content in the Research Portal that you believe breaches copyright or violates any law, please contact openaccess@qub.ac.uk. 


\title{
Comparison Analysis on Damping Mechanisms of Power Systems with Induction Generator Based Wind Power Generation
}

\author{
S. Q. Bu, X. Zhang, J. B. Zhu and X. Liu
}

\begin{abstract}
The rotor structure varies with different types of wind power induction generator (WPIG), which leads to their different dynamic behaviors during power system disturbances. This paper proposes a generic implementation framework of explicit damping torque analysis to investigate the damping mechanisms of power system integrated with induction generator based wind power generation, so that the essential difference and inner connection between two main types of WPIG (i.e., DFIG and FSIG) in damping power system oscillation can be revealed. The linearized models which can represent DFIG and FSIG as well as three transitional wound rotor generators are established to facilitate the analytical comparison analysis. Phillips-Heffron system linearized model is employed to derive an explicit expression of damping torque contribution from main dynamic components of WPIGs. In the paper, 16-machine 5-area NYPS-NETS example system is used for the demonstration of proposed framework and comparison analysis. Both damping effectiveness and robustness of different WPIGs are extensively examined under multiple operating status, in order to provide useful guidance to system planner for the real-time operation of induction generator based wind generation.
\end{abstract}

Index Terms-Damping torque analysis, DFIG, FSIG, model transformation, Phillips-Heffron model, wind power generation.

\section{INTRODUCTION}

\section{A. Background and Motivation}

$I^{2}$ NDUCTION generator based wind power generation has been dominating the wind market since the rise of wind power industry at the end of last century and will be continuously in a favorable position for large-scale grid connection given its lower cost and more mature technology compared with other wind generation for the foreseeable future [1]. Fixed-speed induction generator (FSIG-Type 1 Wind Gen Model) and doubly-fed induction generator (DFIG-Type 3 Wind Gen Model) are two main types of induction generator adopted for wind power generation especially considering the fact that DFIG is the most frequently-used technology to date.

The increasing penetration of wind power generation has significantly affected power system dynamics, e.g., system inertia, which has become smaller but more changeable depending on the wind penetration conditions. Moreover, due to the difference in rotor structures and excitation principles,

S. Q. Bu (corresponding author) is with the Department of Electrical Engineering, The Hong Kong Polytechnic University, Kowloon, H.K. (e-mail: siqi.bu@polyu.edu.hk). X. Zhang and J. B. Zhu are with National Grid,
FSIG and DFIG possess different dynamic behaviors during system disturbances and hence impact the power system dynamics differently, which has posed a big challenge for the real-time system operation and therefore deserves a careful investigation.

\section{B. Literature Review}

The impact of the integration of FSIG and DFIG on power system oscillation stability have been extensively examined from early this century. A comprehensive study regarding the influence of FSIG on power system oscillation is presented in [2] by modal analysis, which considers multiple impact factors including length of transmission interface, load condition, wind penetration level and wind farm configuration etc. It is concluded that in most cases FSIG introduces a negative damping to the system and additional reactive power compensation could mitigate the negative impact of FSIG on oscillation stability. This conclusion is supported by modal analysis in [3] but contradicted by [4]. Compared with FSIG, DFIG is comparatively new and has a more flexible control in active and reactive power, and thus most of research efforts are devoted to the grid connection study of DFIG in recent decade. Various case studies have been implemented to address different aspects of DFIG in affecting the oscillation stability such as integration method [4]-[9], inertia or other sensitivity based approach [10][12], reactive power/voltage control [13][17], operating condition [18], virtual inertia control [19]-[21], additional damping control [22]-[32] and external energy storage system [33][34].

It can be seen from the above review that: 1 . Most of the existing research is actually case-by-case observation by using the two common 'computation' methods (modal analysis \& time domain simulation), and thus the essential reason for inconsistent study results with different preconditions cannot be effectively and convincingly investigated by these two 'black box' methods. No proper theoretical method is seen so far to clearly reveal the essential damping mechanism of power system oscillation stability as affected by FSIG and DFIG; 2. Most of the published research tends to study the grid impact of FSIG and DFIG separately and there is no systematic analytical theory to compare the damping effectiveness and robustness of these two wind power induction generators (WPIGs) and dig deeper information about their essential difference and inner

Wokingham, U.K., RG41 5BN. X. Liu is with the School of Electronics, Electrical Engineering and Computer Science, Queen's University Belfast, Belfast, U.K., BT9 5AH. 
connection in affecting power system oscillations, which will certainly provide a better understanding of their individual damping mechanisms.

\section{Contribution and Structure of This Paper}

Taking account of the points above, a generic methodology to analyze the damping mechanisms of different WPIGs is proposed in this work, with the aim of giving a physical insight that how the different rotor structures and excitation systems of FSIG and DFIG affect their damping mechanisms. The major contributions of the work can be summarized as follows: 1. A generic and explicit analytical method for damping torque analysis of different WPIGs is proposed, which is based in frequency domain but capable of providing deeper understandings about damping mechanisms than modal analysis. Although the focus of this paper is on FSIG and DFIG and the comparison of their different excitation systems, the proposed method can accommodate the case of DFIG with external damping controllers and also it can be further developed to assess the full-converter decoupled generator (Type 4 Wind Gen Model), which will be addressed in the future work; 2. Two typical linearized models and explicit transfer functions of WPIGs (i.e., DFIG and FSIG) are established to facilitate the detailed investigation and comparison of damping mechanisms; 3. Unlike abovementioned numerical comparison (case-by-case study), a purely analytical comparison of damping mechanisms between different WPIGs is implemented and their essential difference and inner connection in damping mechanisms are revealed. Some significant empirical conclusions regarding damping effectiveness and robustness of the two typical WPIGs have been rigorously proved in an analytical manner for the first time.

The rest of paper is organized as follows. In Section II, a general implementation framework of explicit damping torque analysis of Phillips-Heffron model based multi-machine power system is presented. Hence, the closed-form solution of damping torque contribution from the main internal dynamic components of wind generators to each synchronous generator can be derived. Then in Section III, the explicit linearized models of different WPIGs are proposed to accommodate the analytical comparison on the impact mechanisms of DFIG and FSIG, where FSIG is treated as a special case of DFIG with rotor side short-circuit (i.e., rotor voltage equal to zero). In Section IV, the proposed methodology is demonstrated in a 16machine test system and then employed to testify the conclusions of comparison analysis from Section III under different wind penetration conditions. Time domain simulation is employed to prove the accuracy of the proposed methodology

$$
\begin{aligned}
{\left[\begin{array}{c}
\Delta \dot{\delta} \\
\Delta \dot{\omega} \\
\Delta \dot{E}_{q}^{\prime} \\
\Delta \dot{E}_{f d}
\end{array}\right]=} & {\left.\left[\begin{array}{cccc}
0 & \omega_{0} I & 0 & 0 \\
-M^{-1} K_{1} & -M^{-1} D & -M^{-1} K_{2} & 0 \\
-T_{d 0}^{-1} K_{4} & 0 & -T_{d 0}^{-1} K_{3} & T_{d 0}^{-1} \\
-T_{A}^{-1} K_{A} K_{5} & 0 & -T_{A}^{-1} K_{A} K_{6} & -T_{A}^{-1}
\end{array}\right]\left[\begin{array}{c}
\Delta \delta \\
\Delta \omega \\
\Delta E_{q}^{\prime} \\
\Delta E_{f d}
\end{array}\right]+\left[\begin{array}{c}
0 \\
-M^{-1} K_{\omega 1} \\
-T_{d 0}^{-1} K_{E_{q}^{\prime} 1} \\
-T_{A}^{-1} K_{A} K_{E_{f d} 1}
\end{array}\right] \Delta s+\left[\begin{array}{c}
0 \\
-M^{-1} K_{\omega 2} \\
-T_{d 0}^{-1} K_{E_{q}^{\prime}}^{2} \\
-T_{A}^{-1} K_{A} K_{E_{f d} 2}
\end{array}\right] \begin{array}{c}
\Delta E_{d} \\
-M^{-1} K_{\omega 3} \\
-T_{d 0}^{-1} K_{E_{q}^{\prime} 3} \\
-T_{A}^{-1} K_{A} K_{E_{f d} 3}
\end{array}\right] \Delta E_{q} }
\end{aligned}
$$

\section{GENERIC IMPLEMENTATION FRAMEWORK OF EXPLICIT \\ DAMPING TORQUE ANALYSIS OF PHILLIPS-HEFFRON MODEL BASED MULTI-MACHINE POWER SYSTEM WITH WPIGS}

Based on the derivation in Appendix A, the explicit PhillipsHeffron linearized model of a multi-machine power system considering the algebraic interface equations of WPIGs can be established in (1), where state variables ( $\Delta \boldsymbol{\delta}$, $\Delta \boldsymbol{\omega}, \Delta \boldsymbol{E}_{\boldsymbol{q}}^{\prime}$ and $\Delta \boldsymbol{E}_{\boldsymbol{f d}} \quad$ ) and matrix elements $\left(\omega_{0}, M, D, K_{1} \sim K_{6}, T_{d 0}, K_{A}\right.$ and $\left.T_{A}\right)$ of synchronous generators (SGs) are defined in Chapter 3.1 of [35], $\Delta \boldsymbol{s}, \Delta \boldsymbol{E}_{\boldsymbol{d}}$ and $\Delta \boldsymbol{E}_{\boldsymbol{q}}$ is the vector of variation of slip and direct/quadrantaxis electromotive force of WPIGs, and the rest elements $\left(K_{\omega 1}, K_{\omega 2}, K_{\omega 3}, K_{E_{q}^{\prime}{ }^{\prime}}, K_{E_{q}^{\prime}{ }^{\prime}}, K_{E_{q}^{\prime}{ }^{\prime}}, K_{E_{f d} 1}, K_{E_{f d} 2}\right.$ and $\left.K_{E_{f d} 3}\right)$ are calculated in Appendix A. According to (1), it can be noted that: 1. The linearized model presented in (1) is an open-loop system with $\Delta \boldsymbol{s}, \Delta \boldsymbol{E}_{\boldsymbol{d}}$ and $\Delta \boldsymbol{E}_{\boldsymbol{q}}$ as its control variables, since the internal dynamics of WPIGs is not included. Hence, (1) is also named system-side linearized model in this paper; 2 . Only the state variables of induction generator $\left(\Delta \boldsymbol{s}, \Delta \boldsymbol{E}_{\boldsymbol{d}}\right.$ and $\left.\Delta \boldsymbol{E}_{\boldsymbol{q}}\right)$ have a direct impact on the system damping and other state variables (e.g., state variables of DFIG converter controllers) affect system via $\Delta \boldsymbol{s}, \Delta \boldsymbol{E}_{\boldsymbol{d}}$ and $\Delta \boldsymbol{E}_{\boldsymbol{q}}$. For FSIG, $\Delta \boldsymbol{s}$ does not directly contribute to the system damping either since FSIG rotor is a closed circuit and thus physically separate from the grid. However, to keep a consistent form for the demonstration of

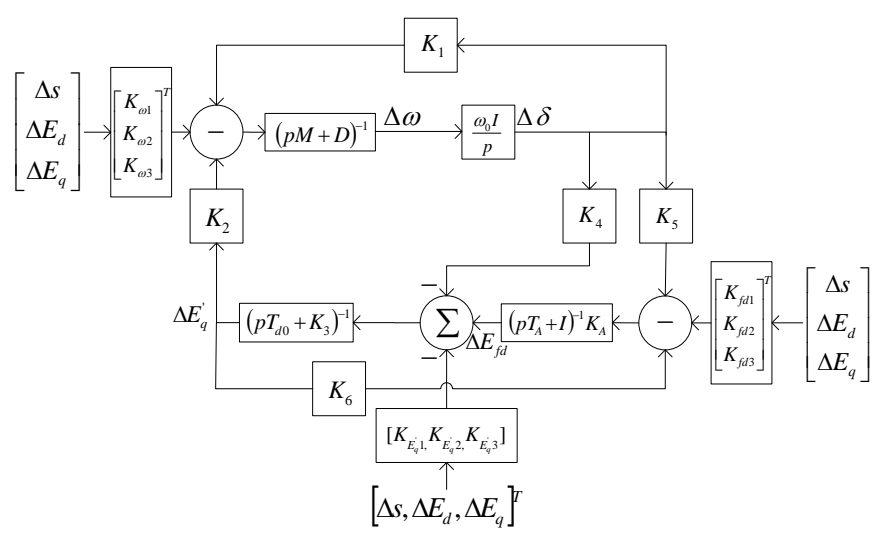

Fig. 1. System-side linearized model diagram of power system integrated with WPIGs. 


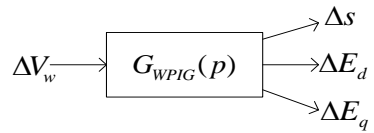

Fig. 2. Representation of WPIG internal dynamics in frequency domain.

WPIG, $\Delta \boldsymbol{s}$ can be retained in (1) but with $K_{\omega 1}=K_{E_{q}^{\prime} 1}=$ $K_{E_{f d} 1}=0$. The linearized model in (1) is illustrated by Fig. 1 in frequency domain and $p$ is the frequency domain operator.

The internal dynamics of WPIG includes that of induction generator and converter controllers (if DFIG), which can be described by a set of first-order differential equations. In frequency domain, these equations can be converted and presented in the form of a SIMO controller as shown in Fig. 2, which will be explained in details in Section III. The input of the controller $\left(\Delta V_{w}\right)$ is terminal voltage associated with WPIG bus, and the outputs of the controller $\left(\Delta s, \Delta E_{d}\right.$ and $\left.\Delta E_{q}\right)$ are three state variables of WPIG as mentioned in (1). Without losing generality, the transfer function is written in a general format as $G_{W P I G}(p)=\left[G_{s}(p), G_{E_{d}}(p), G_{E_{q}}(p)\right]^{T}$, which can represent any type of WPIG. The full representation of $G_{W P I G}(p)$ will be derived in Section III based on the internal dynamics of different types of WPIG.

Fig. 1 and Fig. 2 form a closed-loop linearized system with a clear physical insight. If any system disturbance happens (represented by $\Delta V_{w}$ ), there should be a dynamic response from WPIG (reflected by $\Delta s, \Delta E_{d}$ and $\Delta E_{q}$ ). Then $\Delta s, \Delta E_{d}$ and $\Delta E_{q}$ will in turn impact SGs and hence the system according to Fig. 1. It can be seen that the internal dynamics (i.e., $G_{W P I G}(p)$ ) of WPIG determines its dynamic response and plays a critical role in the dynamic interaction. Therefore, different internal dynamics is actually considered to be the major cause for different types of WPIG to have different damping mechanisms, which is carefully compared and investigated in this work.

Based on the models given in Fig. 1 and Fig. 2, a generic implementation framework of damping torque analysis to evaluate the damping torque contributions from different internal dynamic components of WPIGs and their impact on the system critical oscillation mode is proposed as follows.

The forward path from $\Delta \boldsymbol{s}, \Delta \boldsymbol{E}_{\boldsymbol{d}}$ and $\Delta \boldsymbol{E}_{\boldsymbol{q}}$ to the electromechanical oscillation loop of SGs can be obtained from Fig. 1

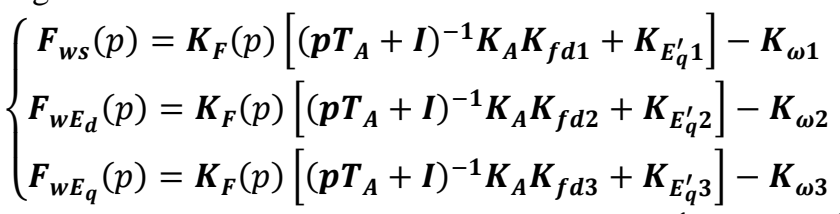

where $\boldsymbol{K}_{F}(p)=\boldsymbol{K}_{\mathbf{2}}\left[\left(p \boldsymbol{T}_{\boldsymbol{d} 0}+\boldsymbol{K}_{3}\right)+\left(p \boldsymbol{T}_{\boldsymbol{A}}+\boldsymbol{I}\right)^{-\mathbf{1}}+\boldsymbol{K}_{\boldsymbol{A}} \boldsymbol{K}_{\mathbf{6}}\right]^{-\mathbf{1}}$, and $\boldsymbol{F}_{\boldsymbol{w}}(p), \boldsymbol{F}_{\boldsymbol{w} \boldsymbol{E}_{\boldsymbol{d}}}(p)$ and $\boldsymbol{F}_{\boldsymbol{w} \boldsymbol{E}_{\boldsymbol{q}}}(p)$ are three $m \times l$ matrices, assuming there are totally $m$ SGs and $l$ WPIGs in the system. Hence, the electric torque provided by the main dynamic components of WPIGs to electromechanical oscillation loop of SGs is

$$
\left\{\begin{array}{l}
\Delta \boldsymbol{T}_{\boldsymbol{w}}=\boldsymbol{F}_{\boldsymbol{w}}(p) \boldsymbol{G}_{\boldsymbol{s}}(p) \Delta \boldsymbol{V}_{\boldsymbol{w}} \\
\Delta \boldsymbol{T}_{\boldsymbol{w} \boldsymbol{E}_{\boldsymbol{d}}}=\boldsymbol{F}_{\boldsymbol{w} \boldsymbol{E}_{\boldsymbol{d}}}(p) \boldsymbol{G}_{\boldsymbol{E}_{\boldsymbol{d}}}(p) \Delta \boldsymbol{V}_{\boldsymbol{w}} \\
\Delta \boldsymbol{T}_{\boldsymbol{w} \boldsymbol{E}_{\boldsymbol{q}}}=\boldsymbol{F}_{\boldsymbol{w} \boldsymbol{E}_{\boldsymbol{q}}}(p) \boldsymbol{G}_{\boldsymbol{E}_{\boldsymbol{q}}}(p) \Delta \boldsymbol{V}_{\boldsymbol{w}}
\end{array}\right.
$$

where $\Delta \boldsymbol{T}_{w s}, \Delta \boldsymbol{T}_{w E_{d}}$ and $\Delta \boldsymbol{T}_{\boldsymbol{w} E_{q}}$ include the electric torque contribution of WPIGs to all SGs and thus are $m$-dimention vectors, and $\Delta \boldsymbol{T}_{w}=\Delta \boldsymbol{T}_{w s}+\Delta \boldsymbol{T}_{w E_{d}}+\Delta \boldsymbol{T}_{w E_{q}}$. It can be revealed that all three dynamic components have their independent system channels to contribute to the system damping torque, which together forms the total damping impact $\Delta \boldsymbol{T}_{w}$ of WPIGs. If the $i^{\text {th }}$ eigenvalue $\lambda_{i}$ is the critical oscillation mode in the system, $\Delta \boldsymbol{V}_{\boldsymbol{w}}$ should be equal to $\boldsymbol{\gamma}_{\boldsymbol{i}} \Delta \omega_{k}$ (see Appendix B). Equation (3) can be further factorized to torque contribution of dynamic components of each WPIG to each SG, and hence the electric torque provided by different dynamics of the $j^{\text {th }}$ WPIG to the $k^{\text {th }}$ SG can be written as

$$
\left\{\begin{array}{l}
\Delta T_{w s k j}=F_{w s k j}\left(\lambda_{i}\right) \boldsymbol{G}_{\boldsymbol{s}}\left(\lambda_{i}\right) \boldsymbol{\gamma}_{i j k} \Delta \omega_{k} \\
\Delta T_{w E_{d} k j}=F_{w E_{d^{k j}}}\left(\lambda_{i}\right) \boldsymbol{G}_{\boldsymbol{E}_{\boldsymbol{d}} j}\left(\lambda_{i}\right) \boldsymbol{\gamma}_{\boldsymbol{i j k}} \Delta \omega_{k} \\
\Delta T_{w E_{q} k j}=F_{w E_{q} k j}\left(\lambda_{i}\right) \boldsymbol{G}_{\boldsymbol{E}_{q j}}\left(\lambda_{i}\right) \boldsymbol{\gamma}_{i j k} \Delta \omega_{k}
\end{array}\right.
$$

where subscript $k$ and $j$ denote the $k^{\text {th }}$ row and $j^{\text {th }}$ column element of corresponding matrices for $F_{w s k j}\left(\lambda_{i}\right), F_{w E_{d} k j}\left(\lambda_{i}\right)$ and $F_{w E_{q} k j}\left(\lambda_{i}\right)$, and the $j^{\text {th }}$ row of corresponding matrices for $\boldsymbol{G}_{\boldsymbol{s} \boldsymbol{j}}\left(\lambda_{i}\right), \boldsymbol{G}_{\boldsymbol{E}_{\boldsymbol{d}} \boldsymbol{j}}\left(\lambda_{i}\right), \boldsymbol{G}_{\boldsymbol{E}_{\boldsymbol{q}} \boldsymbol{j}}\left(\lambda_{i}\right)$ and $\boldsymbol{\gamma}_{\boldsymbol{i j k} \boldsymbol{k}}$. As the electric torque contribution from the $j^{\text {th }}$ WPIG is the linear superposition of each main dynamic component, $\Delta T_{w k j}=\Delta T_{w s k j}+\Delta T_{w E_{d} k j}+$ $\Delta T_{w E_{q} k j}$. Similarly, $\Delta T_{w k}=\sum_{j=1}^{l} \Delta T_{w k j}$, which is the $k^{t h}$ element of $\Delta \boldsymbol{T}_{\boldsymbol{w}}$.

Then the variation of the $i^{\text {th }}$ eigenvalue $\lambda_{i}$ caused by insertion of WPIG dynamics can be assessed by employing $S_{i k}$, the sensitivity of $\lambda_{i}$ with respect to the electric torque coefficient (see Appendix C)

$$
\begin{aligned}
\Delta \lambda_{i} & =\sum_{k=1}^{m} S_{i k} T C_{w k}=\sum_{k=1}^{m} S_{i k} \sum_{j=1}^{l} T C_{w k j} \\
& =\sum_{k=1}^{m} S_{i k} \sum_{j=1}^{l}\left(T C_{w s k j}+T C_{w E_{d} k j}+T C_{w E_{q} k j}\right)
\end{aligned}
$$

where $T C_{w k}$ and $T C_{w k j}$ are the electric torque coefficients of $\Delta T_{w k}$ and $\Delta T_{w k j}$, and $T C_{w s k j}, T C_{w E_{d} k j}$ and $T C_{w E_{q} k j}$ are the coefficients of each main dynamic component in (4) respectively.

On the basis of the derivations above, the generic implementation framework of damping torque analysis of multi-machine power system with WPIGs is established. It can be seen that if closed-form solution of the WPIG transfer function is given, by substituting (2) into (4) and (5), both the damping torque contributions of WPIG dynamics components and eigenvalue variation should have an explicit expression, so that the damping mechanism of WPIGs can be easily examined and revealed. Therefore, the following comparison analysis will be carried out based on the proposed framework.

\section{ANALYTICAL COMPARISON ON DAMPING MECHANISMS OF DIFFERENT TYPES OF WPIGS}

In the presented implementation framework of damping torque analysis, the external damping contribution channels for different types of WPIGs are quite similar as shown in (2) and (3), and hence their transfer functions (internal contribution 
channels) become a crucial part of comparison analysis, which are derived and investigated in this section. To facilitate the comparison and understanding of their damping mechanisms, a five-step model transformation from DFIG to FSIG are employed, in which FSIG is treated as a special case of DFIG. In addition to DFIG and FSIG, three transitional wound rotor generator models are proposed for comparison purposes and the corresponding linearized models are established.

\section{A. Step 1: Detailed DFIG Model}

Since the grid-side converter (GSC) controller of DFIG does not really affect the damping of system oscillation [10][36][37], its dynamics is ignored in this study. The linearized model of DFIGs considering the dynamics of both induction generator and rotor-side converter (RSC) controller is established in (6), where $\boldsymbol{M}_{\boldsymbol{w}}$ is the inertia time constant, $\boldsymbol{D}_{\boldsymbol{w}}$ is the damping coefficient, $\boldsymbol{X}_{p s 1}, \boldsymbol{X}_{p s \mathbf{2}}, \boldsymbol{X}_{q s \mathbf{1}}$ and $\boldsymbol{X}_{q s \mathbf{2}}$ are the state variables of RSC Integral Controllers given by Fig. D1 in Appendix D, and $\boldsymbol{K}_{p s I 1}, \boldsymbol{K}_{p s I 2}, \boldsymbol{K}_{q s I 1}$ and $\boldsymbol{K}_{q s I 2}$ are relevant parameters of Integral Controllers. The explicit form of rest elements $\left(K_{1 w} \sim K_{13 w}, K_{s}, K_{E_{d}}, K_{E_{q}}, K_{X_{p s 1}}, K_{X_{p s 2}}, K_{X_{q s 1}}\right.$ and $\left.K_{X_{q s 2}}\right)$ in (6) is given in Appendix E. As the study focus is on the induction generator and RSC basic control, there is no additional damping control imposed to the RSC controller. The linearized model can also be illustrated in frequency domain as shown in Fig. 3. According to Fig. 3, the transfer functions mentioned in previous section can be extended to their full explicit representation as in (7).

It can be noted from Fig. 3 that: 1. The damping contributions of $\Delta \boldsymbol{s}, \Delta \boldsymbol{E}_{\boldsymbol{d}}$ and $\Delta \boldsymbol{E}_{\boldsymbol{q}}$ to the system mainly consist of two parts, i.e., the dynamics of induction generator and RSC Integral

$$
\begin{gathered}
M_{w}^{-1} K_{1 w} \\
K_{2 w} \\
0 \\
K_{p s I 1} K_{8 w} \\
K_{p s I 2} K_{9 w} \\
0 \\
0
\end{gathered}
$$

Controller, which can be easily differentiated and split. In (7), the induction generator dynamics part of transfer functions includes the items associated with $\boldsymbol{K}_{\boldsymbol{E}_{\boldsymbol{d}}}$ and $\boldsymbol{K}_{\boldsymbol{E}_{\boldsymbol{q}}}$, and the RSC controller dynamics part of transfer functions is associated with RSC controller parameter $\boldsymbol{K}_{p s I 1}, K_{p s I 2}, K_{q s I 1}$ and $\boldsymbol{K}_{q s I 2}$. That is to say, by setting these RSC controller parameters to zero, the damping effect of RSC dynamics is removed.; 2. $\Delta \boldsymbol{E}_{\boldsymbol{d}}$ and $\Delta \boldsymbol{E}_{\boldsymbol{q}}$ have completely separate internal damping contribution channels due to the adoption of decoupled power control of DFIG. $\Delta \boldsymbol{E}_{\boldsymbol{d}}$ is related to the P-Control and $\Delta \boldsymbol{E}_{\boldsymbol{q}}$ is related to the Q-Control; 3. The damping contribution of $\Delta \boldsymbol{S}$ is only affected by its own dynamics and $\Delta \boldsymbol{E}_{\boldsymbol{d}}$ as the rotor motion is mainly determined by the active power control.

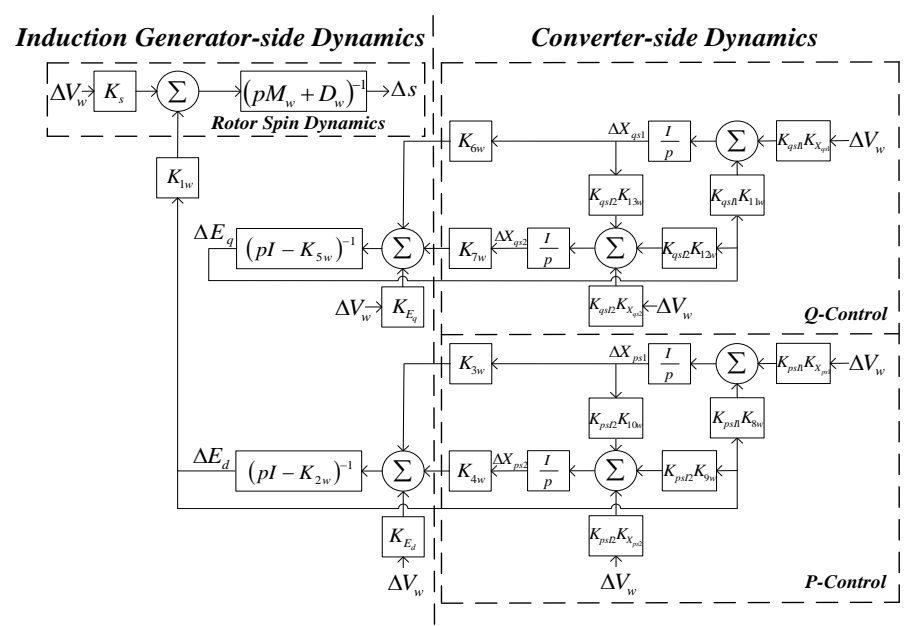

Fig. 3. WPIG-side linearized model diagram (internal dynamics of DFIG).

$\left.\begin{array}{cccc}0 & 0 & 0 & 0 \\ K_{3 w} & K_{4 w} & 0 & 0 \\ 0 & 0 & K_{6 w} & K_{7 w} \\ 0 & 0 & 0 & 0 \\ K_{p s I 2} K_{10 w} & 0 & 0 & 0 \\ 0 & 0 & 0 & 0 \\ 0 & 0 & K_{q s I 2} K_{13 w} & 0\end{array}\right] \times\left[\begin{array}{c}\Delta s \\ \Delta E_{d} \\ \Delta E_{q} \\ \Delta X_{p s 1} \\ \Delta X_{p s 2} \\ \Delta X_{q s 1} \\ \Delta X_{q s 2}\end{array}\right]+\left[\begin{array}{c}M_{w}^{-1} K_{s} \\ K_{E_{d}} \\ K_{E_{q}} \\ K_{p s I 1} K_{X_{p s 1}} \\ K_{p s I 2} K_{X_{p s 2}} \\ K_{q s I 1} K_{X_{q s 1}} \\ K_{q s I 2} K_{X_{q s 2}}\end{array}\right] \Delta V_{w}(6)$




$$
\left\{\begin{array}{c}
\boldsymbol{G}_{E_{d}}(p)=\left\{I-\left(p I-K_{2 w}\right)^{-1}\left[\frac{K_{3 w} K_{p s I 1} K_{\mathbf{8} w}}{p}+\frac{K_{4 w}\left(\frac{K_{p s I 2} K_{10 w} K_{p s I 1} K_{8 w}}{p}+K_{p s I 2} K_{9 w}\right)}{p}\right]\right\}^{-1} \\
\times\left(p I-K_{2 w}\right)^{-1}\left[K_{E_{d}}+\frac{K_{3 w} K_{p s I 1} K_{X_{p s 1}}}{p}+\frac{K_{4 w}\left(\frac{\left.K_{p s I 2} K_{10 w} K_{p s I 1} K_{X_{p s 1}}+K_{p s I 2} K_{X_{p s 2}}\right)}{p}\right]}{p}\right] \\
G_{E_{q}}(p)=\left\{I-\left(p I-K_{5 w}\right)^{-1}\left[\frac{K_{6 w} K_{q s I 1} K_{11 w}}{p}+\frac{K_{7 w}\left(\frac{K_{q s I 2} K_{13 w} K_{q s I 1} K_{11 w}}{p}+K_{q s I 2} K_{12 w}\right)}{p}\right]\right\}^{-1}(7) \\
\times\left(p I-K_{5 w}\right)^{-1}\left[K_{E_{q}}+\frac{K_{6 w} K_{q s I 1} K_{X_{q s 1}}}{p}+\frac{K_{7 w}\left(\frac{\left.K_{q s I 2} K_{13 w} K_{q s I 1} K_{X_{q s 1}}+K_{q s I 2} K_{X_{q s 2}}\right)}{p}\right]}{p}\right] \\
G_{s}(p)=\left(p M_{w}+D_{w}\right)^{-1}\left[K_{s}+K_{1 w} \boldsymbol{G}_{E_{d}}(p)\right]
\end{array}\right.
$$

\section{B. Step 2: DFIG Model without RSC Dynamics}

Normally, the damping effect of RSC Integral Controllers (converter-side dynamics) is limited compared with the RSC Proportional Controllers. In Step 2, converter-side dynamics is not taken into account for the damping analysis and thus the first transitional generator model is obtained. Hence, (6) is reduced to three first-order equations associated with $\Delta \boldsymbol{s}, \Delta \boldsymbol{E}_{\boldsymbol{d}}$ and $\Delta \boldsymbol{E}_{\boldsymbol{q}}$ only.

$$
\begin{aligned}
{\left[\begin{array}{c}
\Delta \dot{S} \\
\Delta \dot{E}_{d} \\
\Delta \dot{E}_{q}
\end{array}\right] } & =\left[\begin{array}{ccc}
-M_{w}^{-1} D_{w} & M_{w}^{-1} K_{1 w} & 0 \\
0 & K_{2 w} & 0 \\
0 & 0 & K_{5 w}
\end{array}\right]\left[\begin{array}{c}
\Delta s \\
\Delta E_{d} \\
\Delta E_{q}
\end{array}\right] \\
& +\left[\begin{array}{c}
M_{w}^{-1} K_{s} \\
K_{E_{d}} \\
K_{E_{q}}
\end{array}\right] \Delta V_{w}
\end{aligned}
$$

The diagram of the linearized model in (8) only includes the left part of Fig. 3 (generator-side dynamics). However, the explicit form and value of elements in (8) remain the same as in (6). As discussed in Step 1, the transfer functions of this transitional generator model should become

$$
\left\{\begin{array}{l}
\boldsymbol{G}_{\boldsymbol{E}_{\boldsymbol{d}}}(p)=\left(p \boldsymbol{I}-\boldsymbol{K}_{\mathbf{2}}\right)^{-\mathbf{1}} \boldsymbol{K}_{\boldsymbol{E}_{\boldsymbol{d}}} \\
\boldsymbol{G}_{\boldsymbol{E}_{\boldsymbol{q}}}(p)=\left(p \boldsymbol{I}-\boldsymbol{K}_{\mathbf{5} \boldsymbol{w}}\right)^{-\mathbf{1}} \boldsymbol{K}_{\boldsymbol{E}_{\boldsymbol{q}}} \\
\boldsymbol{G}_{\boldsymbol{s}}(p)=\left(p \boldsymbol{M}_{\boldsymbol{w}}+\boldsymbol{D}_{\boldsymbol{w}}\right)^{-\mathbf{1}}\left[\boldsymbol{K}_{\boldsymbol{s}}+\boldsymbol{K}_{\mathbf{1} \boldsymbol{w}} \boldsymbol{G}_{\boldsymbol{E}_{\boldsymbol{d}}}(p)\right]
\end{array}\right.
$$

Equation (9) can be also simply obtained by setting $\boldsymbol{K}_{p s I \mathbf{1}}=$ $\boldsymbol{K}_{p s I 2}=\boldsymbol{K}_{\boldsymbol{q s I 1}}=\boldsymbol{K}_{\boldsymbol{q s I 2}}=\mathbf{0}$ in (7).

It can be revealed from Fig. 3 that although dynamics model (Integral Controllers) of RSC controller is removed and only the RSC algebraic model (Proportional Controllers) is retained in this step, the basic configuration of linearized model and damping contribution channels is not changed. In other words, the decoupled structure of damping contribution of $\Delta \boldsymbol{E}_{\boldsymbol{d}}$ and $\Delta \boldsymbol{E}_{\boldsymbol{q}}$ is not determined by the controller dynamics of RSC but actually by offset items of rotor voltage (or named offset rotor voltage) in RSC controller, which is intensively studied in the next step.

\section{Step 3: DFIG Model with Offset Rotor Voltage Only}

On the basis of Step 2, by setting all the parameters of PI controllers of RSC to zero, the second transitional generator model is established. Due to the only existence of offset rotor voltage in RSC, both the rotor dynamic equations associated with $\Delta \boldsymbol{E}_{\boldsymbol{d}}$ and $\Delta \boldsymbol{E}_{q}$ are eliminated $\left(\boldsymbol{K}_{\boldsymbol{E}_{\boldsymbol{d}}}=\boldsymbol{K}_{\boldsymbol{E}_{q}}=\boldsymbol{K}_{2 w}=\right.$ $\boldsymbol{K}_{\mathbf{5}}=\mathbf{0}$ ), and only rotor spin dynamics is retained in this linearized model. Equation (8) becomes

$$
\Delta \dot{s}=-M_{w}^{-1} D_{w} \Delta s+M_{w}^{-1} K_{s} \Delta V_{w}
$$

The diagram of the linearized model in (10) only includes the left upper corner of Fig. 3 (rotor spin dynamics). Based on the diagram, the transfer function of the second transitional generator model is derived to be

$$
\boldsymbol{G}_{\boldsymbol{s}}(p)=\left(p \boldsymbol{M}_{\boldsymbol{w}}+\boldsymbol{D}_{\boldsymbol{w}}\right)^{-\mathbf{1}} \boldsymbol{K}_{\boldsymbol{s}}
$$

It can be seen from (10) that the elimination effect of the offset rotor voltage has removed the 'original' dynamics of induction generator associated with $\Delta \boldsymbol{E}_{\boldsymbol{d}}$ and $\Delta \boldsymbol{E}_{\boldsymbol{q}}$ and the 'new' generator-side dynamics of DFIG presented in Step 1 and 2 are actually brought by the RSC algebraic model (Proportional Controllers) in a decoupled manner. This finding can be also proved by the explicit elements in Appendix E. The key elements of generator-side dynamics $\boldsymbol{K}_{2 \boldsymbol{w}}$ and $\boldsymbol{K}_{\boldsymbol{E}_{\boldsymbol{d}}}$ are mainly affected by the RSC P-Control algebraic model and $\boldsymbol{K}_{\mathbf{5}}$ and $\boldsymbol{K}_{E_{q}}$ are mainly affected by the RSC Q-Control algebraic model, after the introduction of offset rotor voltage. In contrast, $\boldsymbol{K}_{\boldsymbol{s}}$ and $\boldsymbol{K}_{1 \boldsymbol{w}}$ are determined by the induction generator parameter as well as the steady-state operating status, which are not changed by the introduction of either RSC controller or offset rotor voltage.

\section{Step 4: DFIG Model with Constant Rotor Voltage}

Similar to Step 3, the effect of RSC PI controllers is ignored and rotor circuit is still wound in Step 4. The third transitional wound rotor generator model with constant rotor voltage output (sometimes also called open-loop control of RSC converter) is proposed in this step. As the rotor voltage output remains 
constant, the offset items of rotor voltage are removed and hence the 'original' generator-side dynamics is reflected. As a result, the configuration of the linearized model is changed to Fig. 4 and the linearized equations become

$$
\begin{aligned}
{\left[\begin{array}{c}
\Delta \dot{S} \\
\Delta \dot{E}_{d} \\
\Delta \dot{E}_{q}
\end{array}\right] } & =\left[\begin{array}{ccc}
-M_{w}^{-1} D_{w} & M_{w}^{-1} K_{1 w} & 0 \\
K_{2 w} & K_{3 w} & K_{4 w} \\
K_{5 w} & K_{6 w} & K_{7 w}
\end{array}\right]\left[\begin{array}{c}
\Delta s \\
\Delta E_{d} \\
\Delta E_{q}
\end{array}\right] \\
+ & {\left[\begin{array}{c}
M_{w}^{-1} K_{s} \\
0 \\
K_{E_{q}}
\end{array}\right] \Delta V_{w} }
\end{aligned}
$$

where the elements of state matrix have been renumbered due to the change of state matrix configuration in this case and their explicit forms are given in Appendix F. Compared with the elements in Appendix E, most elements in (12) are changed and determined by steady-state value of variables (e.g., $\boldsymbol{K}_{\mathbf{2} w}, \boldsymbol{K}_{\mathbf{4} w}, \boldsymbol{K}_{\mathbf{5} w}$ and $\left.\boldsymbol{K}_{\mathbf{6} w}\right) . \boldsymbol{K}_{\boldsymbol{s}}$ and $\boldsymbol{K}_{\mathbf{1} w}$ remains the same as indicated previously.

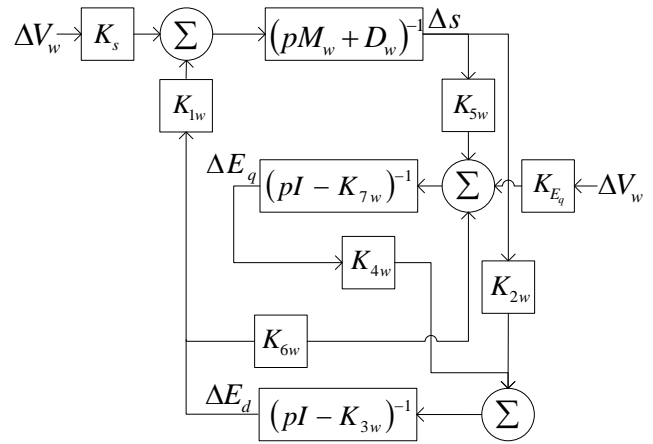

Fig. 4. WPIG-side linearized model diagram (internal dynamics of DFIG with constant rotor voltage or FSIG).

It can be demonstrated from Fig. 4 that the 'original' generator-side dynamics has three significant features: 1 . recoupling of $\Delta \boldsymbol{E}_{\boldsymbol{d}}$ and $\Delta \boldsymbol{E}_{\boldsymbol{q}}$ represented by $\boldsymbol{K}_{\mathbf{4} w}$ and $\boldsymbol{K}_{\mathbf{6} \boldsymbol{w}} ; 2$. Feedback support from $\Delta \boldsymbol{s}$ to $\Delta \boldsymbol{E}_{\boldsymbol{d}}$ and $\Delta \boldsymbol{E}_{\boldsymbol{q}}$ represented by $\boldsymbol{K}_{\mathbf{2} \boldsymbol{w}}$ and $\boldsymbol{K}_{\mathbf{5} \boldsymbol{w}}$; 3. The removal of $\boldsymbol{K}_{\boldsymbol{E}_{\boldsymbol{d}}}$ owing to DFIG d-q reference frame setting. Therefore, the damping mechanism of the third transitional generator model has been dramatically changed, which is also reflected by the transfer functions in (13) where all three transfer functions include $\boldsymbol{K}_{\boldsymbol{s}}$ and $\boldsymbol{K}_{\boldsymbol{E}_{\boldsymbol{q}}}$, and hence are coupled with each other.

\section{E. Step 5: FSIG Model}

In particular condition, if constant rotor voltage in Step 4 is equal to zero, the third transitional wound rotor generator model becomes FSIG with the rotor circuit closed. As a result, the same linearized model ((12) and Fig. 4), transfer functions (13) and damping mechanisms can be applied to FSIG. However, it is worthy to mention that $\Delta \boldsymbol{s}$ of FSIG does not have a direct impact on the system damping as stated in Section II due to the closed physical structure of rotor, although the damping contribution from $\Delta \boldsymbol{s}$ is normally very small.

By implementing the step-by-step model transformation analysis demonstrated above, essential difference and inner connection between DFIG and FSIG in their damping mechanisms of oscillation stability have been clearly revealed. The main points from the comparison analysis are summarized as follows:

1. The damping contributions of DFIG dynamics are essentially from the RSC control, which can be divided into two parts, i.e., the 'new' induction generator dynamics (related to RSC Proportional Controllers) and RSC controller dynamics (related to RSC Integral Controllers). The former represented by the RSC algebraic model normally accounts for the major part of the total damping contributions of DFIG.

2. The existence of the offset rotor voltage in RSC not only enables the decoupled PQ control of DFIG, but also establishes the decoupled structure of internal damping contribution channels of DFIG.

3. FSIG featured by the 'original' induction generator dynamics can be treated as a special case of DFIG model only when the open-loop control of RSC is applied. In this case, the damping contributions of FSIG only comes from the 'original' generator dynamics and are mainly determined by generator parameters and changeable steady-state value of variables as proved by Appendix F. The damping contributions channels of internal dynamics are coupled with each other.

Therefore, based on the main points from the comparison of damping mechanisms of DFIG and FSIG, it can be rigorously concluded that the damping effect of DFIG is more robust since it is mainly determined by generator parameters and RSC controller parameters as proved by Appendix E. On the contrary, the damping impact of FSIG is comparatively limited and less controllable especially in the changing conditions due to the characteristic of 'original' induction generator dynamics.

By substituting the detailed format of transfer functions of DFIG and FSIG derived in (7)(9)(11)(13) into (4) and (5), the proposed damping torque analysis can be carried out.

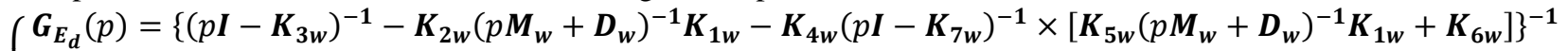

$$
\begin{aligned}
& \times\left\{K_{2 w}\left(p M_{w}+D_{w}\right)^{-1} K_{s}+K_{4 w}\left(p I-K_{7 w}\right)^{-1} \times\left[K_{5 w}\left(p M_{w}+D_{w}\right)^{-1} K_{s}+K_{E_{q}}\right]\right\} \\
& \boldsymbol{G}_{\boldsymbol{s}}(p)=\left(p \boldsymbol{M}_{\boldsymbol{w}}+\boldsymbol{D}_{\boldsymbol{w}}\right)^{-1}\left[\boldsymbol{K}_{\boldsymbol{s}}+\boldsymbol{K}_{\mathbf{1} w} \boldsymbol{G}_{\boldsymbol{E}_{\boldsymbol{d}}}(p)\right] \\
& \left(\boldsymbol{G}_{\boldsymbol{E}_{\boldsymbol{q}}}(p)=\left(p \boldsymbol{I}-\boldsymbol{K}_{\mathbf{7 w}}\right)^{-\mathbf{1}}\left[\boldsymbol{K}_{\mathbf{5} \boldsymbol{w}} \boldsymbol{G}_{\boldsymbol{s}}(p)+\boldsymbol{K}_{\mathbf{6} \boldsymbol{w}} \boldsymbol{G}_{\boldsymbol{E}_{\boldsymbol{d}}}(p)+\boldsymbol{K}_{\boldsymbol{E}_{\boldsymbol{q}}}\right]\right.
\end{aligned}
$$

\section{CASE Study}

To demonstrate the proposed implementation framework and validate the findings from the analytical comparison, 16machine and 68-node NYPS-NETS power system is employed and shown in Fig. 5. The models and parameters of the test system are given in [38]. For demonstration purposes, a WPIG-

based wind farm is planned to be connected to node 15 of the system. The connecting location could be any other nodes in the system, which does not affect the demonstration and validation. The model as well as a typical set of parameters of the WPIG are provided in Appendix D.

\section{A. Base Case Comparison Study}

There are totally four inter-area oscillation modes in this test 


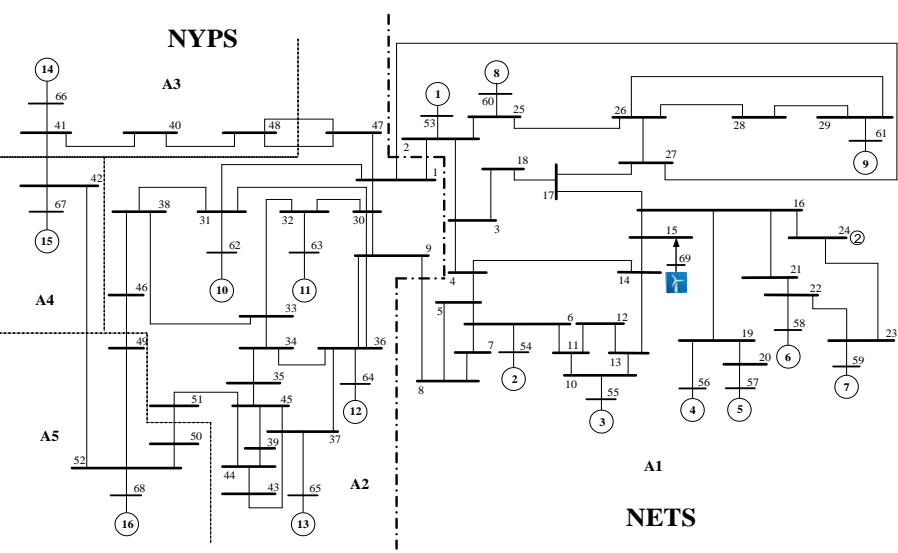

Fig. 5. Diagram of 16-machine 68-bus NYPS-NETS test system integrated with a WPIG.

system and the selection of critical mode would not actually affect the validation of the proposed method and general results from the analytical comparison. Hence, the $31^{\text {st }}$ eigenvalue $\lambda_{31}$ is selected to be the system critical inter-area oscillation mode in the case study here for demonstration purposes. Before the internal dynamics of the WPIG is taken into account, the initial value of this critical inter-area oscillation mode is $\lambda_{31}^{(0)}=$ $-0.1558+j 3.3940$, which is calculated from state matrix of the open-loop system presented in (1). Then due to the limited length of the paper, only two WPIG models (i.e., detailed DFIG model and FSIG model) are demonstrated here.

By adopting (2), the forward paths from the main dynamic components $\left(\Delta s, \Delta E_{d}\right.$ and $\left.\Delta E_{q}\right)$ of the DFIG or FSIG to the electromechanical oscillation loop of SGs are obtained and compared in Table I. It can be seen from Table I that the DFIG has one more external damping contribution channel than FSIG due to the introduction of different algebraic models in (2) brought by different rotor structures, but the sum of the weightings of the external damping contribution channels for the DFIG and FSIG are approximately equal as a whole.

The internal dynamics (transfer functions) of the DFIG and FSIG is computed by using (7) and (13) respectively and compared in Table II.

TABLE I

COMPARISON ON NORM OF FORWARD PATHS (EXTERNAL DAMPING CONTRIBUTION CHANNELS) OF DFIG AND FSIG TO ELECTROMECHANICAL OSCILLATION LOOP OF SGS

\begin{tabular}{|c|c|c|c|c|c|}
\hline & \multicolumn{3}{|c|}{ DFIG MODEL } & \multicolumn{2}{|c|}{ FSIG MODEL } \\
\hline & $\left|F_{w s}\left(\lambda_{31}\right)\right|$ & $\left|\boldsymbol{F}_{\boldsymbol{w} E_{d}}\left(\lambda_{31}\right)\right|$ & $\left|F_{w E_{q}}\left(\lambda_{31}\right)\right|$ & $\left|\boldsymbol{F}_{\boldsymbol{w} E_{d}}\left(\lambda_{31}\right)\right|$ & $\left|F_{w E_{q}}\left(\lambda_{31}\right)\right|$ \\
\hline G1 & 0.0031 & 0.0104 & 0.0151 & 0.0117 & 0.0154 \\
\hline G2 & 0.0034 & 0.0116 & 0.0245 & 0.0130 & 0.0248 \\
\hline G3 & 0.0043 & 0.0147 & 0.0283 & 0.0165 & 0.0287 \\
\hline G4 & 0.0067 & 0.0228 & 0.0502 & 0.0256 & 0.0508 \\
\hline G5 & 0.0041 & 0.0142 & 0.0341 & 0.0160 & 0.0345 \\
\hline G6 & 0.0057 & 0.0193 & 0.0376 & 0.0217 & 0.0382 \\
\hline G7 & 0.0062 & 0.0209 & 0.0380 & 0.0234 & 0.0385 \\
\hline G8 & 0.0038 & 0.0131 & 0.0285 & 0.0147 & 0.0289 \\
\hline G9 & 0.0014 & 0.0052 & 0.0298 & 0.0058 & 0.0301 \\
\hline G10 & 0.0011 & 0.0036 & 0.0081 & 0.0041 & 0.0082 \\
\hline G11 & 0.0020 & 0.0070 & 0.0194 & 0.0079 & 0.0196 \\
\hline
\end{tabular}

\begin{tabular}{|c|c|c|c|c|c|}
\hline G12 & 0.0005 & 0.0017 & 0.0046 & 0.0020 & 0.0047 \\
\hline G13 & 0.0003 & 0.0010 & 0.0020 & 0.0012 & 0.0021 \\
\hline G14 & 0.0001 & 0.0002 & 0.0011 & 0.0003 & 0.0011 \\
\hline G15 & 0.0000 & 0.0000 & 0.0004 & 0.0000 & 0.0004 \\
\hline G16 & 0.0000 & 0.0001 & 0.0011 & 0.0001 & 0.0011 \\
\hline
\end{tabular}

$$
\text { TABLE II }
$$

COMPARISON ON TRANSFER FUNCTIONS (INTERNAL DAMPING CONTRIBUTION

\begin{tabular}{|c|c|c|}
\hline \multicolumn{3}{|c|}{ CHANNELS) OF DFIG AND FSIG } \\
\hline DFIG MODEL & $\Delta V_{w x}$ & $\Delta V_{w y}$ \\
\hline $\boldsymbol{G}_{\boldsymbol{s}}\left(\lambda_{31}\right)$ & $-0.0037-j 0.1560$ & $-0.0009-j 0.0381$ \\
\hline $\boldsymbol{G}_{\boldsymbol{E}_{\boldsymbol{d}}}\left(\lambda_{31}\right)$ & $0.0454-j 0.0049$ & $0.0111-j 0.0012$ \\
\hline $\boldsymbol{G}_{\boldsymbol{E}_{q}}\left(\lambda_{31}\right)$ & $1.1412-j 0.1217$ & $0.2786-j 0.0297$ \\
\hline \hline FSIG MODEL & $\Delta V_{w x}$ & $\Delta V_{w y}$ \\
\hline $\boldsymbol{G}_{\boldsymbol{s}}\left(\lambda_{31}\right)$ & $-0.0074-j 0.0072$ & $-0.0018-j 0.0018$ \\
\hline $\boldsymbol{G}_{\boldsymbol{E}_{d}}\left(\lambda_{31}\right)$ & $0.2208+j 0.0098$ & $0.0539+j 0.0024$ \\
\hline $\boldsymbol{G}_{\boldsymbol{E}_{q}}\left(\lambda_{31}\right)$ & $-0.0907-j 0.2901$ & $-0.0221-j 0.0708$ \\
\hline
\end{tabular}

Table II clearly demonstrates that the main difference of damping mechanisms between the DFIG and FSIG actually lies in their internal damping contribution channels especially in $\boldsymbol{G}_{\boldsymbol{E}_{\boldsymbol{d}}}\left(\lambda_{31}\right)$ and $\boldsymbol{G}_{\boldsymbol{E}_{\boldsymbol{q}}}\left(\lambda_{31}\right)$. Also, since the transfer functions of RSC integral controllers are less than $1 \%$ of each corresponding transfer function of DFIG, they are not listed in Table II separately.

Then the eigenvalue variation caused by the introduction of the DFIG or FSIG main dynamics components are estimated by (5) and shown in Table III.

TABLE III

EIgENVALUE VARIATION BROUGHT BY MAIN DYNAMIC COMPONENTS OF DFIG AND FSIG

\begin{tabular}{|c|c|c|}
\hline & $\Delta \lambda_{31}^{D F I G}$ & $\Delta \lambda_{31}^{F S I G}$ \\
\hline$\Delta s$ & $-0.0008+j 0.0005$ & 0 \\
\hline$\Delta E_{d}$ & $-0.0005-j 0.0007$ & $-0.0016-j 0.0029$ \\
\hline$\Delta E_{q}$ & $-0.0248-j 0.0443$ & $-0.0067+j 0.0061$ \\
\hline Total & $-0.0261-j 0.0446$ & $-0.0082+j 0.0032$ \\
\hline
\end{tabular}

Based on Table III, the estimation of the critical eigenvalue after the insertion of the DFIG or FSIG dynamics can be obtained

$$
\begin{aligned}
& \lambda_{31 \text { est }}^{\text {DFIG }}=\lambda_{31}^{(0)}+\Delta \lambda_{31}^{D F I G}=-0.1819+j 3.3494 \\
& \lambda_{31 \text { est }}^{F S I G}=\lambda_{31}^{(0)}+\Delta \lambda_{31}^{F S I G}=-0.1640+j 3.3972
\end{aligned}
$$

To verify the results in (14), the eigenvalue of the closed-loop system including the DFIG or FSIG dynamics is calculated to be

$$
\begin{aligned}
& \lambda_{31}^{D F I}=-0.1822+j 3.3496 \\
& \lambda_{31}^{F I G}=-0.1640+j 3.3975
\end{aligned}
$$

Therefore, by comparing the results of (14) and (15), the implementation framework of damping torque analysis is validated. It can be summarized from the above comparison analysis that: 1. Both DFIG and FSIG play a positive role in damping power system oscillation for this study case owing to the positive damping impact from each dynamic component; 2. Given the same system network and loading condition, the external damping contribution channels of the DFIG and FSIG tend to be roughly equal. The difference in the total damping effectiveness is essentially brought by their different internal damping contribution channels.

Time domain simulation is also carried out for verification of 
the proposed damping torque analysis. A three-phase shortcircuit fault is applied to node 1 at $0.2 s$ and cleared at $0.3 s$. G5 and G15 are the main generators related to the critical oscillation mode. Hence, the power angle difference between G5 and G15 is plotted in Fig. 6.

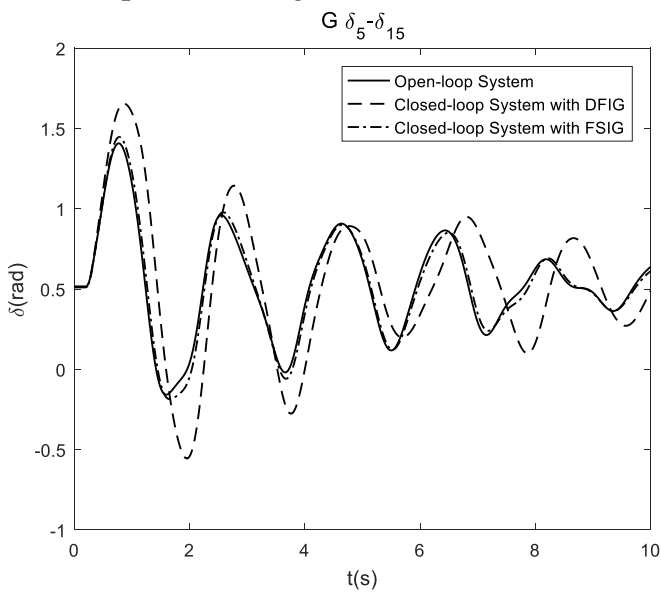

Fig. 6. Observation of G5-G15 power angle curve with different types of WPIG models.

Fig. 6 shows that the non-linear simulation results align with the eigenvalue estimation from frequency domain analysis in Table III and (14). The damping contribution from the FSIG is quite limited, which does not make a notable change to the power oscillation curve compared with the case of open-loop system. The damping effect of the DFIG is better although it has a slightly bigger initial oscillating amplitude.

\section{B. Comparison Study under Different Wind Penetration Conditions}

The damping torque analysis to compare damping effectiveness in a single wind speed condition is demonstrated above. In this subsection, the damping robustness of DFIG and FSIG will be further assessed and compared under different wind penetration conditions. To simulate the intermittence of the wind power in the real case, the power output of DFIG and FSIG is set in a range from the cut-in power $0.2 p . u$. to the rating power 2.0p.u.. As G5 is the main related synchronous generator for the critical oscillation mode, the total damping torque provided by the dynamic components of DFIG and FSIG to G5 is computed by (4) respectively under different wind power levels in Fig. 7. Then the real part of critical eigenvalue of the closed-loop system considering DFIG and FSIG dynamics and open-loop system without any WPIG dynamics are calculated and displayed in Fig. 8.

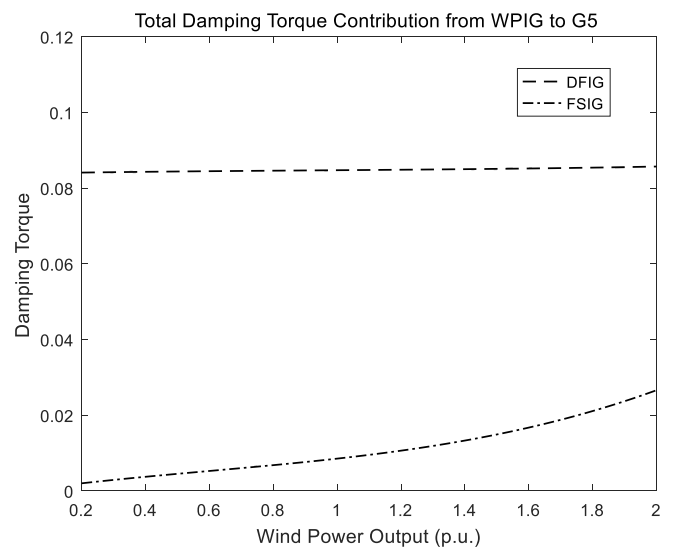

Fig. 7. Comparison on total damping torque provided by DFIG and FSIG under different wind power output levels.

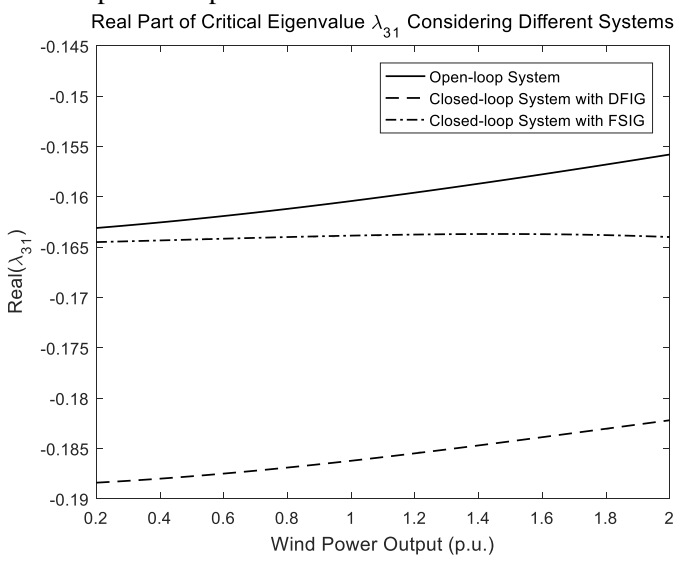

Fig. 8. Comparison on the real part of critical eigenvalue of DFIG and FSIG connected systems under different wind power output levels.

It can be demonstrated by results in Fig. 7 and Fig. 8 that:

1. Although the damping of open-loop system (calculated from (1)) decreases with the increasing wind power, both DFIG and FSIG dynamics contribute a positive damping torque to the critical oscillation mode in this case. Generally, the damping effectiveness of FSIG is limited when compared with DFIG in the same loading condition.

2. The damping torque contribution of DFIG and FSIG in Fig. 7 is in exact proportion to their impact on critical eigenvalue variation in Fig. 8 (i.e., the difference between 'open-loop system' and two 'closed-loop systems').

3. DFIG shows more robustness in damping contribution than FSIG under different wind penetration conditions as it is indicated in Section III that the damping effect of DFIG is mainly determined by generator parameters and RSC control while that of FSIG is affected by generator parameters and changing FSIG operating point. Hence, once the generator is designed, FSIG shows less robustness of damping effect.

\section{CONCLUSIONS}

This paper presents a generic implementation framework of explicit damping mechanism analysis for the Phillips-Heffron model based power system integrated with induction generator based wind power generation. On the basis of proposed methodology, a comprehensive comparison between two typical WPIGs (i.e., DFIG and FSIG) is implemented, in which the explicit linearized models and transfer functions of different WPIGs are established to enable the detailed investigation of 
their damping mechanisms. Then the main findings rigorously derived from the analytical comparison and validated by the designed numerical comparison in the case study can be concluded in the following: 1 . The damping effect of DFIG mainly determined by induction generator parameters and RSC control ('new' induction generator dynamics plus RSC controller dynamics) is more robust under different wind conditions and also more effective if the RSC control parameters are properly tuned; 2 . The damping effect of FSIG determined by induction generator parameters and changeable FSIG operating point ('original' induction generator dynamics) is comparatively limited and less robust in the changing wind conditions; 3 . The inner connection between DFIG and FSIG is that DFIG will degenerate to FSIG and lose its advantageous properties in damping mechanism if open control of RSC is applied. The presented work can effectively facilitate the system planner's understanding of different dynamics of DFIG and FSIG in a complex operational environment.

\section{APPENDIX}

\section{A. Derivation of Equation (1)}

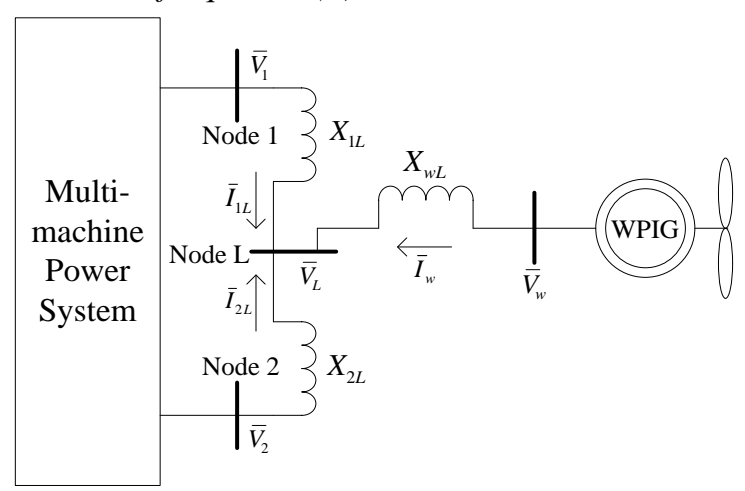

Fig. A1. Diagram of multi-machine power system connected with a WPIG.

Provided that the multi-machine power system is not yet connected with a WPIG, the network equation should be

$$
\left[\begin{array}{c}
0 \\
0 \\
\overline{\boldsymbol{I}}_{\boldsymbol{g}}
\end{array}\right]=\left[\begin{array}{lll}
\bar{Y}_{11} & \bar{Y}_{12} & \overline{\boldsymbol{Y}}_{\mathbf{1 3}} \\
\bar{Y}_{21} & \bar{Y}_{22} & \overline{\boldsymbol{Y}}_{\mathbf{2 3}} \\
\overline{\boldsymbol{Y}}_{\mathbf{3 1}} & \overline{\boldsymbol{Y}}_{\mathbf{3 2}} & \overline{\boldsymbol{Y}}_{\mathbf{3 3}}
\end{array}\right]\left[\begin{array}{c}
\bar{V}_{1} \\
\bar{V}_{2} \\
\overline{\boldsymbol{V}}_{\boldsymbol{g}}
\end{array}\right]
$$

where $\overline{\boldsymbol{V}}_{\boldsymbol{g}}$ and $\overline{\boldsymbol{I}}_{\boldsymbol{g}}$ is the vector of terminal voltage and current associated with SGs. After the WPIG is connected, according to Fig. A1, the network can be written as

$$
\left\{\begin{array}{l}
{\left[\begin{array}{l}
0 \\
0
\end{array}\right]=\left[\begin{array}{cc}
\bar{Y}_{11}^{\prime} & 0 \\
0 & \bar{Y}_{22}^{\prime}
\end{array}\right]\left[\begin{array}{l}
\bar{V}_{1} \\
\bar{V}_{2}
\end{array}\right]+\left[\begin{array}{l}
\bar{I}_{1 L} \\
\bar{I}_{2 L}
\end{array}\right]+\left[\begin{array}{l}
\overline{\boldsymbol{Y}}_{13} \\
\overline{\boldsymbol{Y}}_{\mathbf{2 3}}
\end{array}\right] \overline{\boldsymbol{V}}_{\boldsymbol{g}}} \\
\overline{\boldsymbol{I}}_{\boldsymbol{g}}=\left[\begin{array}{ll}
\overline{\boldsymbol{Y}}_{\mathbf{3 1}} & \overline{\boldsymbol{Y}}_{\mathbf{3 2}}
\end{array}\right]\left[\begin{array}{l}
\bar{V}_{1} \\
\bar{V}_{2}
\end{array}\right]+\overline{\boldsymbol{Y}}_{\mathbf{3 3}} \overline{\boldsymbol{V}}_{\boldsymbol{g}}
\end{array}\right.
$$

where $\bar{Y}_{11}^{\prime}$ and $\bar{Y}_{22}^{\prime}$ exclude $X_{12}=X_{1 L}+X_{2 L}$. Since $\left[\begin{array}{l}\bar{I}_{1 L} \\ \bar{I}_{2 L}\end{array}\right]=$ $\left[\begin{array}{cc}j\left(X_{1 L}+X_{w L}\right) & j X_{w L} \\ j X_{w L} & j\left(X_{2 L}+X_{w L}\right)\end{array}\right]^{-1}\left(\left[\begin{array}{l}\bar{V}_{1} \\ \bar{V}_{2}\end{array}\right]-\left[\begin{array}{l}1 \\ 1\end{array}\right] \bar{V}_{w}\right)$, it obtains

$$
\left[\begin{array}{l}
\bar{V}_{1} \\
\bar{V}_{2}
\end{array}\right]=\overline{\boldsymbol{Y}}_{w}^{-1}\left(\left[\begin{array}{l}
1 \\
1
\end{array}\right] \bar{V}_{w}-\overline{\boldsymbol{Y}}_{\mathbf{L}}\left[\begin{array}{l}
\overline{\boldsymbol{Y}}_{13} \\
\overline{\boldsymbol{Y}}_{23}
\end{array}\right] \overline{\boldsymbol{V}}_{\boldsymbol{g}}\right)
$$

where $\quad \overline{\boldsymbol{Y}}_{\boldsymbol{w}}=\boldsymbol{I}+\left[\begin{array}{cc}j\left(X_{1 L}+X_{w L}\right) & j X_{w L} \\ j X_{w L} & j\left(X_{2 L}+X_{w L}\right)\end{array}\right]\left[\begin{array}{cc}\bar{Y}_{11}^{\prime} & 0 \\ 0 & \bar{Y}_{22}^{\prime}\end{array}\right]$ and $\overline{\boldsymbol{Y}}_{L}=\left[\begin{array}{cc}j\left(X_{1 L}+X_{w L}\right) & j X_{w L} \\ j X_{w L} & j\left(X_{2 L}+X_{w L}\right)\end{array}\right]$. By substituting (A3) into the second equation of (A2), it should have

$$
\begin{aligned}
\overline{\boldsymbol{I}}_{g} & =\left[\begin{array}{ll}
\overline{\boldsymbol{Y}}_{31} & \overline{\boldsymbol{Y}}_{32}
\end{array}\right] \overline{\boldsymbol{Y}}_{w}^{-1}\left[\begin{array}{l}
1 \\
1
\end{array}\right] \bar{V}_{w} \\
& +\left(\overline{\boldsymbol{Y}}_{33}-\left[\begin{array}{ll}
\overline{\boldsymbol{Y}}_{31} & \overline{\boldsymbol{Y}}_{32}
\end{array}\right] \overline{\boldsymbol{Y}}_{w}^{-1} \overline{\boldsymbol{Y}}_{L}\left[\begin{array}{l}
\overline{\boldsymbol{Y}}_{13} \\
\overline{\boldsymbol{Y}}_{23}
\end{array}\right]\right) \overline{\boldsymbol{V}}_{g}
\end{aligned}
$$

By linearizing (A3), it gives

$$
\left[\begin{array}{l}
\Delta V_{1} \\
\Delta V_{2}
\end{array}\right]=Y_{w}^{-1}\left(Y_{I} \Delta V_{w}-Y_{L}\left[\begin{array}{l}
Y_{13} \\
Y_{23}
\end{array}\right] \Delta V_{g}\right)
$$

where $\Delta V_{1}=\left[\begin{array}{ll}\Delta V_{1 x} & \Delta V_{1 y}\end{array}\right]^{T}$ and same form applies to other variables. $\boldsymbol{Y}_{\boldsymbol{I}}=\left[\begin{array}{llll}1 & 0 & 1 & 0 \\ 0 & 1 & 0 & 1\end{array}\right]^{\mathbf{T}}, \boldsymbol{Y}_{\boldsymbol{w}}^{-\mathbf{1}}$ and $\boldsymbol{Y}_{\boldsymbol{L}}$ are the expanded form of $\overline{\boldsymbol{Y}}_{\boldsymbol{w}}^{-\mathbf{1}}$ and $\overline{\boldsymbol{Y}}_{\boldsymbol{L}}$ respectively. Equation (A4) can be also linearized to be

$$
\begin{aligned}
\Delta I_{g} & =\left[\begin{array}{ll}
Y_{31} & Y_{32}
\end{array}\right] Y_{w}^{-1} Y_{I} \Delta V_{w} \\
& +\left(\bar{Y}_{33}-\left[\begin{array}{ll}
Y_{31} & Y_{32}
\end{array}\right] Y_{w}^{-1} Y_{L}\left[\begin{array}{l}
Y_{13} \\
Y_{23}
\end{array}\right]\right) \Delta V_{g}
\end{aligned}
$$

As $\bar{I}_{w}=-\left(\bar{I}_{1 L}+\bar{I}_{2 L}\right)$ and $\bar{V}_{L}=\bar{V}_{w}-j X_{w L} \bar{I}_{w}$, it can have

$$
\bar{I}_{w}=\bar{Y}_{1} \bar{V}_{w}+\bar{Y}_{2}\left[\begin{array}{l}
\bar{V}_{1} \\
\bar{V}_{2}
\end{array}\right]
$$

where

$$
\bar{Y}_{1}=-\frac{j\left(X_{1 L}+X_{2 L}\right)}{X_{1 L} X_{2 L}+X_{2 L} X_{w L}+X_{w L} X_{1 L}} \quad \text { and } \quad \bar{Y}_{2}=
$$

$\frac{j\left[\begin{array}{ll}X_{2 L} & X_{1 L}\end{array}\right]}{X_{1 L} X_{2 L}+X_{2 L} X_{w L}+X_{w L} X_{1 L}}$. (A7) can be linearized to be

$$
\Delta I_{w}=Y_{1} \Delta V_{w}+Y_{2}\left[\begin{array}{l}
\Delta V_{1} \\
\Delta V_{2}
\end{array}\right]
$$

By substituting (A5) into (A8) and eliminating $\left[\begin{array}{l}\Delta V_{1} \\ \Delta V_{2}\end{array}\right]$, it gives

$$
\Delta I_{w}=\left(Y_{1}+Y_{2} Y_{w}^{-1} Y_{I}\right) \Delta V_{w}-Y_{2} Y_{w}^{-1} Y_{L}\left[\begin{array}{l}
Y_{13} \\
Y_{23}
\end{array}\right] \Delta V_{g}
$$

As the standard algebraic linearized model of a WPIG can be written as $\Delta \boldsymbol{I}_{\boldsymbol{w}}=\boldsymbol{C}_{\boldsymbol{w}} \Delta \boldsymbol{X}_{\boldsymbol{w}}+\boldsymbol{D}_{\boldsymbol{w}} \Delta \boldsymbol{V}_{\boldsymbol{w}}$, where $\Delta \boldsymbol{X}_{\boldsymbol{w}}=$ $\left[\begin{array}{lll}\Delta s & \Delta E_{d} & \Delta E_{q}\end{array}\right]^{T}$, By eliminating $\Delta \boldsymbol{I}_{\boldsymbol{w}}$, (A9) becomes

$$
\begin{aligned}
\Delta V_{w}= & \left(Y_{1}-D_{w}+Y_{2} Y_{w}^{-1} Y_{I}\right)^{-1}\left[C_{w} \Delta X_{w}\right. \\
& \left.+Y_{2} Y_{w}^{-1} Y_{L}\left[\begin{array}{l}
Y_{13} \\
Y_{23}
\end{array}\right] \Delta V_{g}\right]
\end{aligned}
$$

By substituting (A10) into (A6), $\Delta \boldsymbol{V}_{\boldsymbol{w}}$ is eliminated

$\Delta I_{g}=\left[\begin{array}{ll}Y_{31} & Y_{32}\end{array}\right] Y_{w}^{-1} Y_{I}\left(Y_{1}-D_{w}+Y_{2} Y_{w}^{-1} Y_{I}\right)^{-1} C_{w} \Delta X_{w}+$ $\left(\begin{array}{c}\bar{Y}_{33}-\left[\begin{array}{cc}Y_{31} & Y_{32}\end{array}\right] Y_{w}^{-1} Y_{L}\left[\begin{array}{l}Y_{13} \\ Y_{23}\end{array}\right]+\left[\begin{array}{ll}Y_{31} & Y_{32}\end{array}\right] Y_{w}^{-1} Y_{I} \\ \left(Y_{1}-D_{w}+Y_{2} Y_{w}^{-1} Y_{I}\right)^{-1} Y_{2} Y_{w}^{-1} Y_{L}\left[\begin{array}{l}Y_{13} \\ Y_{23}\end{array}\right] \Delta V_{g}\end{array}\right) \Delta$

Then the reference frame transformation from $x-y$ to $d-q$ is applied to (A11). After substituting the linearized form of the synchronous generator equation $\overline{\boldsymbol{V}}_{\boldsymbol{g}}=\overline{\boldsymbol{E}}_{q}^{\prime}-\boldsymbol{j} \boldsymbol{X}_{\boldsymbol{d}}^{\prime} \overline{\boldsymbol{I}}_{\boldsymbol{g}}-\boldsymbol{j}\left(\boldsymbol{X}_{q}-\right.$ $\left.\boldsymbol{X}_{\boldsymbol{d}}^{\prime}\right) \overline{\boldsymbol{I}}_{\boldsymbol{q}}$ into (A11) under d-q frame, $\Delta \boldsymbol{V}_{\boldsymbol{g}}$ in (A11) is eliminated and (A11) should have the form

$$
\Delta \boldsymbol{I}_{g}=\boldsymbol{R}_{\delta} \Delta \boldsymbol{\delta}+\boldsymbol{R}_{E_{q}^{\prime}} \Delta \boldsymbol{E}_{q}^{\prime}+\boldsymbol{R}_{I_{q}} \Delta \boldsymbol{I}_{q}+\boldsymbol{R}_{X_{w}} \Delta \boldsymbol{X}_{\boldsymbol{w}}
$$

Hence, $\Delta \boldsymbol{I}_{\boldsymbol{g}}$ is converted to $\Delta \boldsymbol{I}_{\boldsymbol{d}}$ and $\Delta \boldsymbol{I}_{\boldsymbol{q}}$, and (A12) becomes

$$
\begin{aligned}
& \Delta \boldsymbol{I}_{d}=\boldsymbol{R}_{\delta d} \Delta \boldsymbol{\delta}+\boldsymbol{R}_{E_{q}^{\prime} d} \Delta \boldsymbol{E}_{q}^{\prime}+\boldsymbol{R}_{I_{q} d} \Delta \boldsymbol{I}_{q}+\boldsymbol{R}_{X_{w} d} \Delta \boldsymbol{X}_{w} \\
& \Delta I_{q}=R_{\delta q} \Delta \delta+R_{E_{q}^{\prime} q} \Delta E_{q}^{\prime}+R_{I_{q} q} \Delta I_{q}+R_{X_{w} q} \Delta X_{w}
\end{aligned}
$$

Finally, (A13) is substituted into the following linearized model of multi-machine power system given in (A14) [35] and hence the form of Eq. (1) can be derived. 


$$
\begin{aligned}
& \Delta \dot{\delta}=\omega_{0} \Delta \omega \\
& \Delta \dot{\omega}=M^{-1}\left(\Delta T_{E}-D \Delta \omega\right) \\
& \Delta \dot{E}_{q}^{\prime}=T_{d 0}^{-1}\left(-\Delta E_{Q}+\Delta E_{f d}\right) \\
& \Delta \dot{E}_{f d}=\left(-\Delta E_{f d}-K_{A} \Delta V_{g}\right) T_{A}^{-1}
\end{aligned}
$$

where $\Delta \boldsymbol{T}_{E}=\Delta \boldsymbol{I}_{q} \boldsymbol{E}_{q 0}^{\prime}+\boldsymbol{I}_{q 0} \Delta \boldsymbol{E}_{q}^{\prime}+\Delta \boldsymbol{I}_{q}\left(\boldsymbol{X}_{q}-\boldsymbol{X}_{d}^{\prime}\right) \boldsymbol{I}_{d 0}$

$+\boldsymbol{I}_{q 0}\left(\boldsymbol{X}_{q}-\boldsymbol{X}_{d}^{\prime}\right) \Delta \boldsymbol{I}_{d}, \Delta \boldsymbol{E}_{Q}=\Delta \boldsymbol{E}_{q}^{\prime}-\left(\boldsymbol{X}_{\boldsymbol{d}}-\boldsymbol{X}_{d}^{\prime}\right) \Delta \boldsymbol{I}_{\boldsymbol{d}}$

and $\Delta \boldsymbol{V}_{g d}=\boldsymbol{X}_{q} \Delta \boldsymbol{I}_{q}, \Delta \boldsymbol{V}_{g q}=\Delta \boldsymbol{E}_{q}^{\prime}-\boldsymbol{X}_{d}^{\prime} \Delta \boldsymbol{I}_{\boldsymbol{d}}$.

The above derivation can be extended to accommodate the case of multiple WPIGs.

\section{B. Derivation of $\gamma_{i k}$}

According to the algebraic equation of the linearized model of a multi-machine power system with WPIGs, it can obtain

$$
\Delta \boldsymbol{V}_{w}=\boldsymbol{C}_{\boldsymbol{V}_{w} X_{g}} \Delta \boldsymbol{X}_{g}
$$

where $\Delta \boldsymbol{X}_{\boldsymbol{g}}$ is the vector of state variables associated with SGs. If $\lambda_{i}$ and $\boldsymbol{v}_{i}$ is the $i^{\text {th }}$ eigenvalue and associated right eigenvector of state matrix in (1), it can have

$$
\Delta \boldsymbol{X}_{\boldsymbol{g}}=\sum_{i=1}^{n} \frac{v_{\boldsymbol{i g}} a_{i}}{p-\lambda_{i}}, \Delta \omega_{k}=\sum_{i=1}^{n} \frac{v_{i k} a_{i}}{p-\lambda_{i}}
$$

where $\boldsymbol{v}_{\boldsymbol{i g}}$ is the vector inside $\boldsymbol{v}_{\boldsymbol{i}}$ corresponding to $\Delta \boldsymbol{X}_{\boldsymbol{g}}$, and $\boldsymbol{v}_{i k}$ is the element of $\boldsymbol{v}_{\boldsymbol{i}}$ corresponding to $\Delta \omega_{k}$ (angular speed of the $k^{\text {th }} \mathrm{SG}$ ). Based on (B1) and (B2), the relationship between $\Delta \boldsymbol{V}_{\boldsymbol{w}}$ and $\Delta \omega_{k}$ can be derived.

$$
\Delta \boldsymbol{V}_{\boldsymbol{w}}=\boldsymbol{C}_{\boldsymbol{V}_{\boldsymbol{w}} \boldsymbol{X}_{\boldsymbol{g}}}\left(\sum_{i=1}^{n} \frac{v_{\boldsymbol{i g}} a_{i}}{p-\lambda_{i}} / \sum_{i=1}^{n} \frac{v_{i k} a_{i}}{p-\lambda_{i}}\right) \Delta \omega_{k}=\boldsymbol{\gamma}_{\boldsymbol{i k}} \Delta \omega_{k}
$$

\section{Derivation of $S_{i k}$}

The sensitivity of $\lambda_{i}$ with respect to the electric torque coefficient can be computed to be

$$
S_{i k}=\frac{\partial \lambda_{i}}{\partial T C_{w k}}=w_{i k} v_{i k}
$$

where $w_{i k}$ is the element of $\lambda_{i}$ associated left eigenvector $\boldsymbol{w}_{\boldsymbol{i}}$ corresponding to $\Delta \omega_{k}$.

\section{DFIG/FSIG Models and Parameters}

\section{D.1 Induction Generator Parameters}

$M_{w}=3.4 s, D_{w}=0, R_{r}=0.0007, X_{s}=0.0878, X_{r}=$ 0.0373, $X_{m}=1.3246, X_{r 3}=0.05, X_{s s}=X_{s}+X_{m}, X_{r r}=$ $X_{r}+X_{m}, P_{w}=2.0$ p.u.,$V_{w}=1.015 p . u$.

\section{2 Converter Control System Model and Parameters}

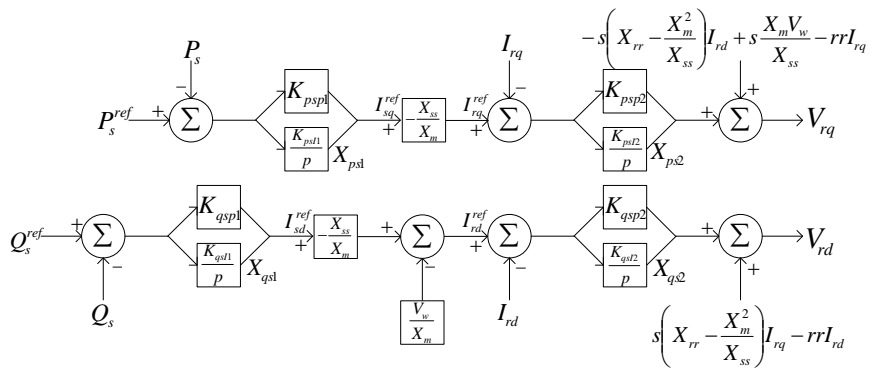

Fig. D1. Configuration of RSC control system model of DFIG.

RSC controller parameters:

$K_{p s p 1}=K_{q s p 1}=0.2, K_{p s p 2}=K_{q s p 2}=1$,

$K_{p s I 1}=K_{q s I 1}=12.56 s^{-1}, K_{p s I 2}=K_{q s I 2}=62.5 s^{-1}$
E. Explicit Form of Elements in Equation (6), (8) and (10)

$K_{1 w}=I_{s d 0}+\frac{X_{r r} E_{q 0}}{X_{s}^{2}-X_{s s} X_{r r}}, K_{2 w}=\frac{K_{p s p 2} X_{s s}}{X_{s s} X_{r r}-X_{r}^{2}}\left(I+K_{p s p 1}\left|V_{w 0}\right|\right)$,

$K_{3 w}=\frac{K_{p s p 2} X_{s s}}{X_{r r}}, K_{4 w}=-\frac{X_{m}}{X_{r r}}, K_{5 w}=\frac{K_{q s p 2} X_{s s}}{X_{s s} X_{r r}-X_{m}^{2}}\left(I+K_{q s p 1}\left|V_{w 0}\right|\right)$,

$K_{6 w}=-\frac{K_{q s p 2} X_{s s}}{X_{r r}}, K_{7 w}=\frac{X_{m}}{X_{r r}}, K_{8 w}=\frac{X_{r r}\left|V_{w 0}\right|}{X_{s s} X_{r r}-X_{m}^{2}}$,

$K_{9_{w}}=\frac{X_{s s} X_{r r}}{\left(X_{m}^{2}-X_{s s} X_{r r}\right) X_{m}}\left(I+K_{p s p 1}\left|V_{w 0}\right|\right), K_{10 w}=-\frac{X_{s s}}{X_{m}}$,

$K_{11 w}=\frac{X_{r r}\left|V_{w 0}\right|}{X_{m}^{2}-X_{s s} X_{r r}}, K_{12 w}=\frac{X_{s s} X_{r r}}{\left(X_{s s} X_{r r}-X_{m}^{2}\right) X_{m}}\left(I+K_{q s p 1}\left|V_{w 0}\right|\right)$,

$K_{13 w}=-\frac{X_{s s}}{X_{m}}, K_{s}=\frac{X_{s s} E_{d 0}\left[\begin{array}{ll}V_{w x} & V_{w y 0}\end{array}\right]}{\left(X_{m}^{2}-X_{s s} X_{r r}\right)\left|V_{w 0}\right|}$

$K_{E_{d}}=-\frac{K_{p s p 1} K_{p s p 2} X_{s s} I_{s q 0}\left[\begin{array}{ll}S_{w x 0} & V_{w y 0}\end{array}\right]}{X_{r r}\left|V_{w 0}\right|}$

$K_{E_{q}}$

$=\frac{\boldsymbol{K}_{q s p 2} \boldsymbol{X}_{s s}\left[-\frac{\boldsymbol{X}_{r r}\left|\boldsymbol{V}_{w 0}\right|}{\boldsymbol{X}_{s s} \boldsymbol{X}_{r r}-\boldsymbol{X}_{m}^{2}}+\boldsymbol{K}_{q s p 1}\left(\boldsymbol{I}_{s d 0}-\frac{\boldsymbol{X}_{r r}\left|\boldsymbol{V}_{w 0}\right|}{\boldsymbol{X}_{s S} \boldsymbol{X}_{r r}-\boldsymbol{X}_{m}^{2}}\right)\right]\left[\begin{array}{ll}\boldsymbol{V}_{w x 0} & \boldsymbol{V}_{w y 0}\end{array}\right]}{\boldsymbol{X}_{r r}\left|\boldsymbol{V}_{w 0}\right|}$

$\boldsymbol{K}_{X_{p s 1}}=-\frac{\boldsymbol{I}_{s q 0}\left[\begin{array}{ll}V_{w x 0} & V_{w y 0}\end{array}\right]}{\left|\boldsymbol{V}_{w 0}\right|}, \boldsymbol{K}_{X_{p s 2}}=\frac{\boldsymbol{K}_{p s p 1} X_{s s} I_{s q 0}\left[\begin{array}{ll}V_{w x 0} & V_{w y 0}\end{array}\right]}{X_{m}\left|V_{w 0}\right|}$,

$\boldsymbol{K}_{X_{q s 1}}=\left(-\frac{I_{s d 0}}{\left|V_{w 0}\right|}+\frac{X_{r r}}{X_{s s} X_{r r}-X_{m}^{2}}\right)\left[\begin{array}{ll}V_{w x 0} & V_{w y 0}\end{array}\right]$

$K_{X_{q s 2}}=\frac{X_{s s}}{X_{m}\left|V_{w 0}\right|}\left[K_{q s p 1}\left(I_{s d 0}-\frac{X_{r r}\left|V_{w 0}\right|}{X_{s s} X_{r r}-X_{m}^{2}}\right)-\frac{X_{r r}}{X_{s s} X_{r r}-X_{m}^{2}}\right]$

$\left[\begin{array}{ll}V_{w x 0} & V_{w y 0}\end{array}\right]$

where the subscript 0 denotes the steady-state value of variables, d-q denotes the WPIG reference frame and $x-y$ denotes the system reference frame (applicable to Appendix F).

F. Explicit Form of Elements in Equation (12)

$K_{1 w}=I_{s d 0}+\frac{X_{r r} E_{q 0}}{X_{m}^{2}-X_{s s} X_{r r}}, K_{2 w}=E_{q 0}, K_{3 w}=K_{7 w}=\frac{R_{r} X_{s s}}{X_{m}^{2}-X_{s s} X_{r r}}$,

$K_{4 w}=s_{0}, K_{5 w}=-E_{d 0}, K_{6 w}=-s_{0}, K_{s}=\frac{X_{s s} E_{d 0}\left[\begin{array}{ll}V_{w x 0} & V_{w y 0}\end{array}\right]}{\left(X_{m}^{2}-X_{s s} X_{r r}\right)\left|V_{w 0}\right|^{\prime}}$

$K_{E_{q}}=\frac{R_{r} X_{m}^{2}\left[\begin{array}{ll}V_{w x 0} & V_{w y 0}\end{array}\right]}{\left(X_{m}^{2}-X_{s s} X_{r r}\right)\left|V_{w 0}\right|}$

\section{ACKNOWLEDGMENT}

The authors would like to acknowledge the support from Department of Electrical Engineering, Hong Kong Polytechnic University for the Start-up Fund Research Project (1-ZE68), and Research Grant Council (HK) for the Early Career Scheme Grant Research Project (25203917).

\section{REFERENCES}

[1] Global Wind Energy Council, Global Wind Report, Annual Market Update 2016, available online: http://www.gwec.net/.

[2] D. Thakur and N. Mithulananthan, "Influence of Constant Speed Wind Turbine Generator on Power System Oscillation," Electric Power Components and Systems, vol. 37, pp. 478-494, 2009.

[3] H. M. Fayek, I. Elamvazuthi, N. Perumal, and B. Benkatesh, "The Impact of DFIG and FSIG Wind Farms on the Small Signal Stability of a Power System," $5^{\text {th }}$ International Conference on Intelligent and Advanced Systems, pp. 1-6, 2014.

[4] J. G. Slootweg, W. L. Kling, "The Impact of Large Scale Wind Power Generation on Power System Oscillations," Electric Power Systems Research, vol. 67, pp. 9-20, 2003.

[5] F. Mei, B. C. Pal, "Modal Analysis of a Grid-Connected Doubly Fed Induction Generator," IEEE Trans. Energy Conversion, vol. 22, no. 3, pp. 728-736, Sept. 2007.

[6] F. Wu, X. P. Zhang, K. Godfrey and P. Ju, "Small Signal Stability Analysis and Optimal Control of a Wind Turbine with Doubly Fed Induction Generator," IET Gener. Transm. Distrib., vol. 1, no. 5, pp. 751760, Sept. 2007. 
[7] J. J. Sanchez-Gasca, N. W. Miller and W. W. Price, "A Modal Analysis of a Two-Area System with Significant Wind Power Penetration," Power Systems Conference and Exposition, vol. 2, pp. 1148-1152, Oct. 2004.

[8] A. Mendonca, and J. A. Pecas Lopes, "Impact of Large Scale Wind Power Integration on Small Signal Stability," Future Power Systems, pp. 1-5, Nov. 2005.

[9] J. Quintero, V. Vittal, G. T. Heydt and H. Zhang, "The impact of increased penetration of converter control-based generators on power system modes of oscillation," IEEE Trans. Power Syst., vol. 29, no. 5, pp. 2248-2256, Sept. 2014.

[10] D. Gautam, V. Vittal and Terry Harbour, "Impact of Increased Penetration of DFIG-Based Wind Turbine Generators on Transient and Small Signal Stability of Power Systems," IEEE Trans. Power Systems, vol. 24, no. 3 , pp. 1426-1434, Aug. 2009.

[11] M. Garmroodi, D. J. Hill, G. Verbic and J. Ma, "Impact of Tie-Line Power on Inter-Area Modes With Increased Penetration of Wind Power," IEEE Trans. Power Systems, vol. 31, no. 4, pp. 3051-3060, July 2016.

[12] M. Jafarian and A. M. Ranjbar, "Interaction of the dynamics of doubly fed wind generators with power system electromechanical oscillations," IET Renewable Power Generation, vol. 7, no. 2, pp. 89-97, Nov. 2012.

[13] E. Vittal, M. O'Malley, and A. Keane, "Rotor angle stability with high penetrations of wind generation," IEEE Trans. Power Syst., vol. 27, no. 1, pp. 353-362, Feb. 2012.

[14] E. Vittal and A. Keane, "Identification of critical wind farm locations for improved stability and system planning," IEEE Trans. Power Syst., vol. 28, no. 3, pp. 2950-2958, Aug. 2013.

[15] G. Tsourakis, B. M. Nomikos and C. D. Vournas, "Effect of wind parks with doubly fed asynchronous generators on small-signal stability," Elect. Power Syst. Res., vol. 79, no. 1, pp. 190-200, Jan. 2009.

[16] L. Fan, Z. Miao and D. Osborn, "Impact of doubly fed wind turbine generation on inter-area oscillation damping," in Proc. IEEE Power Eng. Soc. General Meeting, 2008, pp. 1-8.

[17] G. Tsourakis, B. M. Nomikos and C. D. Vournas, "Contribution of doubly fed wind generators to oscillation damping," IEEE Trans. Energy Convers., vol. 24, no. 3, pp. 783-791, Sep. 2009.

[18] L. P. Kunjumuhammed, B. C. Pal, K. K. Anaparthi, and N. F. Thornhill, "Effect of wind penetration on power system stability," in Proc. IEEE Power and Energy Soc. General Meeting (PES), Vancouver, BC, Canada, Jul. 2013, pp. 1-5.

[19] D. Gautam, L. Goel, R. Ayyanar, V. Vittal and T. Harbour, "Control Strategy to Mitigate the Impact of Reduced Inertia Due to Doubly Fed Induction Generators on Large Power Systems," IEEE Trans. Power Systems, vol. 26, no. 1, pp. 214-224, Feb. 2011.

[20] M. F. M. Arani and E. F. E1-Saadany, "Implementing Virtual Inertia in DFIG-Based Wind Power Generation," IEEE Trans. Power Systems, vol. 28, no. 2, pp. 214-224, May 2013.

[21] J. Ma, Y. Qiu, W. B. Zhang, Z. X. Song and J. S. Thorp, "Research on the Impact of DFIG Virtual Inertia Control on Power System Small-Signal Stability Considering the Phase-Locked Loop," IEEE Trans. Power Systems, vol. PP, no. 99, pp. 1-12, 2016.

[22] D. Rimorov, I. Kamwa and G. Joós, "Quasi-Steady-State Approach for Analysis of Frequency Oscillations and Damping Controller Design," IEEE Trans. Power Syst., vol. 31, no. 4, pp. 3212-3220, Jul. 2016.

[23] D. Rimorov, G. Joós and I. Kamwa, "Design and Implementation of Combined Frequency/Oscillation Damping Controller for Type 4 Wind Turbines," 2016 Power Systems Computation Conference (PSCC), pp. 17, 2016.

[24] J. Dominguez-Garcia, F. D. Bianchi and O. Gomis-Bellmunt, "Control Signal Selection for Damping Oscillations With Wind Power Plants Based on Fundamental Limitations," IEEE Trans. Power Syst., vol. 28, no. 4, pp. 4274-4281, Nov. 2013.

[25] M. F. M. Arani and Y. Mohamed, "Analysis and Impacts of Implementing Droop Control in DFIG-Based Wind Turbines on Microgrid/Weak-Grid Stability," IEEE Trans. Power Syst., vol. 30, no. 1, pp. 385-396, Jan. 2015.

[26] T. Surinkaew and I. Ngamroo, "Coordinated Robust Control of DFIG Wind Turbine and PSS for Stabilization of Power Oscillations Considering System Uncertainties," IEEE Trans. Sustainable Energy, vol. 5, no. 3, pp. 823-833, July 2014.

[27] T. Surinkaew and I. Ngamroo, "Hierarchical Co-Ordinated Wide Area and Local Controls of DFIG Wind Turbine and PSS for Robust Power Oscillation Damping," IEEE Trans. Sustainable Energy, vol. 7, no. 3, pp. 943-955, July 2016.

[28] Y. Liu, J. R. Gracia, T. J. King and Y. L. Liu, "Frequency Regulation and Oscillation Damping Contributions of Variable-Speed Wind Generators in the U.S. Eastern Interconnection (EI)," IEEE Trans. Sustainable Energy, vol. 6, no. 3, pp. 951-958, July 2015.

[29] L. Zeni, R. Eriksson, S. Goumalatsos, M. Altin, P. Sorensen, A. Hansen. P. Kjar, and B. Hesselbak, "Power Oscillation Damping From VSCHVDC Connected Offshore Wind Power Plants," IEEE Trans. Power Delivery, vol. 31, no. 2, pp. 829-838, Apr. 2016.

[30] M. Singh, A. J. Allen, E. Muljadi, V. Gevorgian, Y. C. Zhang and S. Santoso, "Interarea Oscillation Damping Controls for Wind Power Plants," IEEE Trans. Sustainable Energy, vol. 6, no.3, pp. 967-975, July 2015.

[31] Y. Mishra, S. Mishra, F. X. Li, Z. Y. Dong and R. C. Bansal, "SmallSignal Stability Analysis of a DFIG-Based Wind Power System Under Different Modes of Operation," IEEE Trans. Energy Conversion, vol. 24, no.4, pp. 972-982, Dec. 2009.

[32] M. Mokhtari and F. Aminifar, "Toward Wide-Area Oscillation Control Through Doubly-Fed Induction Generator Wind Farms," IEEE Trans. Power Syst., vol. 29, no. 6, pp. 2985-2992, Nov. 2014.

[33] S. Chandra, D. F. Gayme, and A. Chakrabortty, "Coordinating Wind Farms and Battery Management Systems for Inter-Area Oscillation Damping: A Frequency-Domain Approach," IEEE Trans. Power Syst., vol. 29, no. 3, pp. 1454-1462, May 2014.

[34] A. Jamehbozorg and G. Radman, "Small-signal analysis of power systems with wind and energy storage units," IEEE Trans. Power Syst., vol. 30, no. 1, pp. 298-305, Jan. 2015.

[35] Y. N. Yu, Electric Power System Dynamics. New York: Academic Press, 1983.

[36] J. M. Rodriguez, J. L. Fernandez, D. Beato, R. Iturbe, J. Usaola, P. Ledesma, and J. R. Wilhelmi, "Incidence on power system dynamics of high penetration of fixed speed and doubly fed wind energy systems: study of the spanish case," IEEE Trans. Power Systems, vol. 17, no. 4, pp. 1089-1095, Nov. 2002.

[37] CIGRE Technical Brochure on Modeling and Dynamic Behavior of Wind Generation as it Relates to Power System Control and Dynamic Performance, Working Group 01, Advisory Group 6, Study Committee C4, Draft Rep., Aug. 2006.

[38] G. Rogers, Power System Oscillations. Norwell, MA, USA: Kluwer, 2000.

\section{BIOGRAPHIES}

S. Q. Bu received the Ph.D. degree from the electric power and energy research cluster, the Queen's University of Belfast, Belfast, U.K., in 2012, where he continued his postdoctoral research work before entering industry. Subsequently, he joined National Grid UK as a Power System Engineer and then became an experienced UK National Transmission System Planner and Operator. He has received various prizes due to excellent performances and outstanding contributions in operational and commissioning projects. He is an Assistant Professor with Hong Kong Polytechnic University and also a Chartered Engineer with UK Engineering Council. His research interests are power system stability analysis and operation control, including wind power generation, PEV, HVDC, FACTS and ESS

X. Zhang works as a Power System Engineer at National Grid UK. He received the B.Eng. degree in Automation at Shandong University in 2006, the M.Sc. degree (with distinction) and Ph.D. degree in Electrical Power Engineering from the University of Manchester in 2007 and 2010. His main research interests include high voltage engineering such as electrical arcs, and power system planning, operation and control.

J. B. Zhu received the B.S. degree in microelectronics from Nankai University, Tianjin, China, and the M.Sc. and Ph.D. degrees in electronic and electrical engineering from the University of Strathclyde, Glasgow, U.K., in 2008, 2009 and 2013 respectively. He joined in National Grid UK in 2013 as a power system modeling engineer and later on worked as transmission network development strategy engineer. He is currently acting as an electricity national control room engineer responsible for Scotland transmission real-time security. His research interests involve with wind power generation, VSC-HVDC transmission system, ESS and micro-grid DC applications.

X. Liu received the Ph.D. degree in electrical and electronic engineering from Queen's University Belfast (QUB), Belfast, U.K., in 2009. Her Ph.D. work on algorithm development in 'moving window kernel PCA for adaptive monitoring of nonlinear processes' is ranked third among the most cited CILS 
journal articles published since 2009. Currently, she is a Lecturer with the Energy, Power and Intelligent Control Cluster at QUB. Her research interests include the development of advanced data-analysis tools for smart-grid widearea monitoring and protective control. 